\title{
Slow to Anger and Fast to Forgive: Cooperation in an Uncertain World
}

\section{Citation}

Anna Dreber, Drew Fudenberg, and David G. Rand. 2012. Slow to anger and fast to forgive: cooperation in an uncertain world. American Economic Review 102(2): 720-749.

\section{Permanent link}

http://nrs.harvard.edu/urn-3:HUL.InstRepos:11223697

\section{Terms of Use}

This article was downloaded from Harvard University's DASH repository, and is made available under the terms and conditions applicable to Open Access Policy Articles, as set forth at http:// nrs.harvard.edu/urn-3:HUL.InstRepos:dash.current.terms-of-use\#OAP

\section{Share Your Story}

The Harvard community has made this article openly available.

Please share how this access benefits you. Submit a story.

\section{Accessibility}




\title{
Slow to Anger and Fast to Forgive: \\ Cooperation in an Uncertain World
}

\author{
Drew Fudenberg, David G. Rand, and Anna Dreber*
}

Abstract: We study the experimental play of the repeated prisoner's dilemma when intended actions are implemented with noise. In treatments where cooperation is an equilibrium, subjects cooperate substantially more than in treatments without cooperative equilibria. In all settings there was considerable strategic diversity, indicating that subjects had not fully learned the distribution of play. Furthermore, cooperative strategies yielded higher payoffs than uncooperative strategies in the treatments with cooperative equilibria. In these treatments successful strategies were "lenient" in not retaliating for the first defection, and many were "forgiving" in trying to return to cooperation after inflicting a punishment.

Repeated games with observed actions have a great many equilibrium outcomes when players are patient, as shown by various folk theorems. ${ }^{1}$ These theorems show that cooperative play is possible when players are concerned about future rewards and punishments, but since repeated play of a static equilibrium is always an equilibrium of the repeated game, the folk theorems do no predict that cooperation will in fact occur. Intuition and evidence (e.g. Robert Axelrod 1984; Pedro Dal Bó 2005; Anna Dreber et al 2008; Dal Bó and Guillaume Frechette 2009; John Duffy and Jack Ochs 2009) suggest that in repeated games with observed actions players do indeed tend to cooperate when

\footnotetext{
* Fudenberg: Department of Economics, Harvard University, 1805 Cambridge Street, Cambridge MA 02138, USA (email: dfudenberg@harvard.edu); Rand: Program for Evolutionary Dynamics, Harvard University, 1 Brattle Square Suite 6, Cambridge MA 02138, USA (email: drand@fas.harvard.edu); Dreber: SIFR, Drottninggatan 89, 11360 Stockholm, Sweden (email: anna.dreber@sifr.org). Fudenberg and Rand are co-lead authors. We are grateful to Pedro Dal Bó and Guillaume Frechette for sharing their data and code with us, and for taking the time to reply to our numerous queries. We thank Rob Boyd, Armin Falk, Simon Gächter, Edward Glaeser, Stephanie Hurder, Guido Imbens, Magnus Johannesson, Martin Nowak, Parag Pathak, Thomas Pfeiffer and John Scholz for helpful conversations and comments, and three referees for useful reports. Research support was provided by National Science Foundation grants SES-064816 and SES- 0951462, the Dean of the Faculty of Arts and Sciences, and David Rand is supported by a grant from the John Templeton Foundation.

${ }^{1}$ James W. Friedman (1971), Robert J. Aumann and Lloyd S. Shapley (1994) and Drew Fudenberg and Eric Maskin (1986).
} 
there is a cooperative equilibrium, at least if the gains to cooperation are sufficiently large. ${ }^{2}$

Outside of the laboratory, actions are often observed with noise: someone who claims they worked hard, or that they were too busy or sick to help, may or may not be telling the truth, and an awkward or inconvenient action may have been well-intentioned; similarly, a self-interested action may wind up accidentally benefiting another. In this setting too, there can be equilibria in which players do better than in the one-shot play of the game, as seen for example in the trigger-strategy equilibria constructed by Edward $\mathrm{J}$. Green and Robert H. Porter (1984), and indeed a version of the folk theorem applies to repeated games with imperfect public monitoring provided, as shown by Fudenberg, David K. Levine and Maskin (1994). ${ }^{3}$ Moreover, while there are evolutionary arguments for cooperation in repeated games with perfectly observed actions, the evolutionary arguments for cooperative equilibria are even stronger with imperfect observations, as the possibility that punishment may be triggered by "mistake" decreases the viability of unrelenting or grim strategies that respond to a single bad observation by never cooperating again. ${ }^{4}$

This paper studies experimental play of the repeated prisoner's dilemma when intended actions are implemented with noise. Our main goals are to understand whether and when subjects play cooperatively, and also to get a sense of the sorts of strategies that they use. We present evidence from four different payoff specifications for a repeated prisoner's dilemma, with stage game actions "Cooperate" ("C") and "Defect" ("D") (neutral language was used in the experiment itself); the difference in specifications was

\footnotetext{
${ }^{2}$ Dal Bó (2005) and Dal Bó and Frechette (2011) find that there need not be cooperation when the gain from cooperation is small. Earlier papers had found less cooperative play than these studies, but as Dal Bó (2005) discusses these papers had various methodological flaws, such as subjects playing vs. an experimenter instead of each other, or extremely low payments.

${ }_{3}^{3}$ Public monitoring means that all players observe a public signal whose distribution depends on the actions played, as in the work of Dilip Abreu, David Pearce and Ennio Stachetti (1990). The noisy games we study have public monitoring, and satisfy the "identifiability" conditions that are needed for the folk theorem.

${ }^{4}$ Axelrod and William D. Hamilton (1981) applied the ESS solution concept to a small subset of the repeated game strategies. Fudenberg and Maskin (1990, 1994) and Ken Binmore and Larry Samuelson (1992) and show that ESS predicts cooperation in the prisoner's dilemma with noisy observations even when all finite-complexity strategies are allowed. Robert Boyd (1989) notes that noise permits cooperative strategies to be evolutionarily stable, but in his framework non-cooperative strategies are stable as well. A parallel literature considers explicit evolutionary dynamics on a restricted strategy space; this includes Marcus W. Feldman and Ewart A.C. Thomas (1987), Martin A. Nowak and Karl Sigmund (1990), and Nowak et al. (2004) for the case of observed actions, and Nowak and Sigmund (1993) and Lorens A. Imhof, Fudenberg and Nowak (2007) for repeated games with noise.
} 
the benefit that playing "C" gives to the other player. We consider these four payoff specifications with a continuation probability of $7 / 8$ and an error rate of $1 / 8$. As controls we also consider error rates of 1/16 and 0 (no exogenously imposed error at all) under the "most cooperative" payoff specification, i.e. that with highest benefit to cost ratio. We find that there is much more cooperation in specifications where there is a "cooperative equilibrium" (an equilibrium in which players initially cooperate, and continue to do so at least until a D is observed): players cooperate $49-61 \%$ of the time in treatments with cooperative equilibria, compared to $32 \%$ in the specification without cooperative equilibria. In these specifications, we also find that cooperative strategies yielded higher payoffs than uncooperative ones. Conversely, in the one treatment where "Always Defect" is the only equilibrium, this strategy was the most prevalent and had the highest payoff.

As compared to experiments on the prisoner's dilemma without noise, which we review in Section II, subjects were markedly more lenient (slower to resort to punishment). For example, in the payoff treatments that support cooperation, we find that subjects played $\mathrm{C}$ in $63-77 \%$ of the rounds immediately following their partner's first defection, compared to only $13-42 \%$ in the cooperative treatments of Dal Bó and Frechette (2011), Dreber et al. (2008) and our no-error control, which are the no-error games we will be using for comparison throughout. ${ }^{5}$ Subjects also showed a considerable level of forgiveness (willingness to give cooperation a second chance): in the noisy specifications with cooperative equilibria, our subjects returned to playing $\mathrm{C}$ in $18-33 \%$ of rounds immediately following the breakdown of cooperation, as compared to $6-28 \%$ in the games without error. ${ }^{6}$ Consistent with these findings, subjects are more likely to condition on play more than one round ago in the noisy treatments than in the no-error games; $65 \%$ use strategies with longer memories in presence of error, compared to $28 \%$ in the games without error.

\footnotetext{
5 These statistics describe cooperation after one's partner defects for the first time, rather than overall cooperation. We find similar levels of overall cooperation without noise (78\%) and with low noise of $1 / 16$ $(82 \%)$, but substantially less overall cooperation with high noise $1 / 18(59 \%)$.

${ }^{6}$ This describes histories in which (i) at least one subject chose $\mathrm{C}$ in the first round, (ii) in at least one previous round, the initially cooperative subject chose $C$ while the other subject chose D and (iii) in the immediately previous round the formerly cooperative subject played D.
} 
In addition to such descriptive statistics, we more explicitly explore which strategies our subjects used, using the techniques of Dal Bó and Frechette (2011). ${ }^{7}$ Relatively few subjects used the strategy "Tit-for-Tat" (TFT) which was prevalent in the Dal Bó and Frechette (2011) experiment, or the strategy "Perfect Tit-for-Tat" (PTFT, also called "Win-Stay, Lose-Shift") which is favored by evolutionary game theory in treatments where it is an equilibrium if players are restricted to strategies that depend only on the previous round's outcome, as is commonly assumed in that literature. ${ }^{8}$ Instead, the most prevalent cooperative strategies were "Tit-for-2-Tats" (TF2T, punish once after two defections), "2-Tits-for-2-Tats" (2TF2T, punish two times after two defections), both of which are forgiving, and modified, lenient versions of the Grim strategy, which wait for two or three defections before abandoning cooperation. These results, and other descriptive measures of subjects' play, show that subjects can and do use strategies that look back more than one round, at least in games with noise.

We find considerable strategic diversity in all settings: No strategy has probability of greater than $30 \%$ in any treatment, and typically three or four strategies seem prevalent. Moreover, in every treatment a substantial number of players seem to use ALLD ("Always Defect"). That strategy does quite poorly in treatments where most of the subjects are playing strategies that are conditionally cooperative, but it is a best response to the belief that most other subjects play ALLD. Similarly, a substantial fraction of agents cooperate in the treatment where ALLD earns the highest payoff. We take this as evidence that learning was incomplete, and that it is difficult to learn the optimal response to the prevailing distribution of play. ${ }^{9}$

An alternative explanation for the diversity of play is that it reflects a distribution of social preferences, with some subjects preferring to cooperate even if it does not maximize their own payoffs, and others playing to maximize the difference between their

\footnotetext{
${ }^{7}$ In section III we summarize the findings of Claus Wedekind and Manfred Milinski (1996) and Masaki Aoyagi and Frechette (2009), who also analyzed the strategies used in a repeated prisoner's dilemma, and of Jim Engle-Warnick and Robert L. Slonim (2006), who examined the strategies used in a trust game. With the exception of Aoyagi and Frechette, these experiments considered environments without noise; the introduction of noise leads more information sets to be reached and so makes it easier to distinguish between strategies.

${ }^{8}$ The explicit analysis of evolutionary dynamics becomes quite difficult when longer memories are possible.

${ }^{9}$ We used a continuation probability of $7 / 8$, instead of the $1 / 2$ and $3 / 4$ in Dal Bó and Frechette (2011), to investigate the extent to which players condition on observations before the previous round. When the continuation probability is $1 / 2$, many interactions will last three or fewer rounds, which makes it hard to study how far back players look in choosing their actions.
} 
partner's payoff and their own. To test this alternative hypothesis, we had subjects play a dictator game at the end of the session, with payoffs going to recipients recruited at a later experimental session, and we also asked subjects to fill out a post-experiment survey on attitudes and motivations. In another paper (Dreber, Fudenberg and David G. Rand 2010) we explore this possibility; our main conclusion is that when the selfish payoffs strongly support cooperation, social preferences do not seem to be a key factor in explaining who cooperates and what strategies they use. Leniency and forgiveness seem to be motivated by strategic concerns rather than social preferences.

\section{Experimental Design}

The purpose of the experimental design is to test what happens when subjects play an infinitely repeated prisoner's dilemma with error. The infinitely repeated game is induced by having a known constant probability that the interaction will continue between two players following each round. We let the continuation probability be $\delta=7 / 8$. With probability $1-\delta$, the interaction ends and subjects are informed that they have been re-matched with a new partner. There is also a known constant error probability that an intended move is changed to the opposite move. Our main conditions use $E=1 / 8$; we also ran control conditions with $\mathrm{E}=1 / 16$ and $\mathrm{E}=0$. Subjects were informed when their own move has been changed (i.e. when they make an error), but not when the other player's move has been changed; they were only notified of the other player's actual move, not the other's intended move. Subjects were informed of all of the above in the experimental instructions, which are included in the online appendix.

The stage game is the prisoner's dilemma in Figure 1 where the payoffs are denoted in points. Cooperation and defection take the "benefit/cost" (b/c) form, where cooperation means paying a cost $\mathrm{c}$ to give a benefit $\mathrm{b}$ to the other player, while defection gives 0 to each party; $\mathrm{b} / \mathrm{c}$ took the values $1.5,2,2.5$, and 4 in our four different treatments. ${ }^{10}$ Subjects were presented with both the b/c representation and the resulting pre-error payoff matrix, in neutral language (the choices were labeled A and B as opposed to the "C vs. D" choice that is standard in the prisoner's dilemma). We used the

\footnotetext{
${ }^{10}$ This payoff specification gives us a simple one-parameter ordering of the treatments; we do not think it is essential for our results. Note that the specification implies that the short-run gain to playing D instead of C is independent of the other player's action. The prisoner's dilemma is more general than this; its defining characteristics are that $\mathrm{D}$ is a dominant strategy and that both playing $\mathrm{C}$ yields the highest payoff - in particular both playing $\mathrm{C}$ should be more efficient than alternating between $(\mathrm{C}, \mathrm{D})$ and $(\mathrm{D}, \mathrm{C})$.
} 
exchange rate of 30 units $=\$ 1$. Subjects were given a show-up fee of $\$ 10$ plus their winnings from the repeated prisoner's dilemma and an end-of session dictator game. To allow for negative stage-game payoffs, subjects began the session with an "endowment" of 50 units (in addition to the show-up fee). ${ }^{11}$ On average subjects made $\$ 22$ per session, with a range from $\$ 14$ to $\$ 36$. Sessions lasted approximately 90 minutes. $^{12}$

A total of 384 subjects voluntarily participated at the Harvard Decision Science Laboratory in Cambridge, MA. In each session, 12-32 subjects interacted anonymously via computer using the software Z-Tree (Urs Fischbacher 2007) in a sequence of infinitely repeated prisoner's dilemmas (see Table 1 for summary statistics on the different treatments). We conducted a total of 18 sessions between September 2009 and October $2010 .{ }^{13}$ We only implemented one treatment during a given session, so each subject participated in only one treatment. To rematch subjects after the end of each repeated game, we used the turnpike protocol as in Dal Bó (2005). Subjects were divided into two equally-sized groups, A and B. A-subjects only interacted with B-subjects and vice versa, so that no subject ever played twice with another subject, or with a subject who has played with a subject they have played with, so that subjects could not influence the play of subjects they interacted with in the future. ${ }^{14}$ Subjects were informed about this setup. To implement random game lengths we pre-generated a sequence of integers $t_{1}, t_{2}, .$. according to the specified geometric distribution to use in all sessions, such that in each session every first interaction lasted $t_{1}$ rounds, every second interaction lasted $t_{2}$ etc. $^{15}$

\footnotetext{
${ }^{11}$ No subject ever had fewer than 19 units, and only 4 out of 278 subjects ever dropped below 40 units.

${ }^{12}$ Subjects were given at most 30 seconds to make their decision, and informed that after 30 seconds a random choice would be made. The average decision time was 1.3 seconds, much less than the 30 second limit, and the frequency of random decisions was very low, 0.0055 .

${ }^{13}$ All sessions were conducted during the academic year, and all subjects were recruited through the CLER lab at Harvard Business School using the same recruitment procedure. Subject demographics varied relatively little across sessions and treatments. See online appendix for demographic summary statistics by session.

${ }^{14}$ Thus the maximum number of interactions in a session with $\mathrm{N}$ subjects was $\mathrm{N} / 2$, and in each session we ran the maximum number of interactions. This explains why the average number of interactions differs between the different treatments. The average numbers of interactions per subject in Table 1 are not integers because there were multiple sessions per treatment.

${ }^{15}$ The starting place in the sequence of random game lengths that was used in the experiment was picked by the programmer, and the sequence following the chosen starting place had an unusually low number of short games. As a result the overall distribution of game lengths differed from what would be expected from a geometric distribution, which raises the concern that the subjects could have noticed this and adjusted their play. However, analysis of the data shows that subjects did not become less likely to cooperate in later rounds over the course of the session; see the online appendix for details.
} 
Figure 1. Payoff matrices for each specification. Payoffs are denoted in points.

\section{Realized payoffs}

$\mathrm{b} / \mathrm{c}=1.5$

\begin{tabular}{l|c|c|}
\multicolumn{1}{c}{} & \multicolumn{1}{c}{$\mathrm{C}$} & \multicolumn{1}{c}{$\mathrm{D}$} \\
\cline { 2 - 3 } $\mathrm{C}$ & 1,1 & $-2,3$ \\
\cline { 2 - 3 } $\mathrm{D}$ & $3,-2$ & 0,0 \\
\cline { 2 - 3 } & &
\end{tabular}

$\mathrm{b} / \mathrm{c}=2$

\begin{tabular}{c|c|c|} 
& \multicolumn{1}{c}{$\mathrm{C}$} & \multicolumn{1}{c}{$\mathrm{D}$} \\
\cline { 2 - 3 } $\mathrm{C}$ & 2,2 & $-2,4$ \\
\cline { 2 - 3 } $\mathrm{D}$ & $4,-2$ & 0,0 \\
\cline { 2 - 3 } & &
\end{tabular}

$\mathrm{b} / \mathrm{c}=2.5$

\begin{tabular}{l|c|c|}
\multicolumn{1}{c}{} & \multicolumn{1}{c}{$\mathrm{C}$} & \multicolumn{1}{c}{$\mathrm{D}$} \\
\cline { 2 - 3 } $\mathrm{C}$ & 3,3 & $-2,5$ \\
\cline { 2 - 3 } $\mathrm{D}$ & $5,-2$ & 0,0 \\
\cline { 2 - 3 } & &
\end{tabular}

$\mathrm{b} / \mathrm{c}=4$

\begin{tabular}{c|c|c|}
\multicolumn{1}{c}{} & \multicolumn{1}{c}{$\mathrm{C}$} & \multicolumn{1}{c}{$\mathrm{D}$} \\
\cline { 2 - 3 } $\mathrm{C}$ & 6,6 & $-2,8$ \\
\cline { 2 - 3 } $\mathrm{D}$ & $8,-2$ & 0,0 \\
\cline { 2 - 3 } & &
\end{tabular}

\section{Expected payoffs}

$\mathrm{b} / \mathrm{c}=1.5, \mathrm{E}=1 / 8$

\begin{tabular}{c|c|c|} 
& \multicolumn{1}{c}{$\mathrm{C}$} & $\mathrm{D}$ \\
\cline { 3 - 4 } $\mathrm{C}$ & $0.875,0.875$ & $-1.375,2.375$ \\
\cline { 2 - 3 } $\mathrm{D}$ & $2.375,-1.375$ & $0.125,0.125$ \\
\cline { 2 - 3 } & \multicolumn{2}{|c}{} \\
\end{tabular}

$\mathrm{b} / \mathrm{c}=2, \mathrm{E}=1 / 8$

\begin{tabular}{l|c|c|}
\multicolumn{1}{c}{} & \multicolumn{1}{c}{$\mathrm{C}$} & $\mathrm{D}$ \\
\cline { 3 - 3 } $\mathrm{C}$ & $1.75,1.75$ & $-1.25,3.25$ \\
\cline { 2 - 3 } $\mathrm{D}$ & $3.25,-1.25$ & $0.25,0.25$ \\
\cline { 2 - 3 } & &
\end{tabular}

$\mathrm{b} / \mathrm{c}=2.5, \mathrm{E}=1 / 8$

\begin{tabular}{l|c|c|}
\cline { 2 - 3 } $\mathrm{C}$ & $2.625,2.625$ & $-1.125,4.125$ \\
\cline { 2 - 3 } $\mathrm{D}$ & $4.125,-1.125$ & $0.375,0.375$ \\
\cline { 2 - 3 }
\end{tabular}

$\mathrm{b} / \mathrm{c}=4, \mathrm{E}=1 / 8$

\begin{tabular}{|c|c|c|}
\hline & $\mathrm{C}$ & D \\
\hline & $5.25,5.25$ & $-0.75,6.75$ \\
\hline & $6.75,-0.75$ & $0.75,0.75$ \\
\hline
\end{tabular}

$\mathrm{b} / \mathrm{c}=4, \mathrm{E}=1 / 16$

$\mathrm{C}$

D

C $5.625,5.625 \quad-1.375,7.375$

D $7.375,-1.375 \quad 0.375,0.375$

Table 1. Summary statistics for each treatment.

\begin{tabular}{|lcccccc|}
\hline & $\begin{array}{c}\mathbf{b} / \mathbf{c}=\mathbf{1 . 5} \\
\mathbf{E}=\mathbf{1 / 8}\end{array}$ & $\begin{array}{c}\mathbf{b} / \mathbf{c}=\mathbf{2} \\
\mathbf{E}=\mathbf{1 / 8}\end{array}$ & $\begin{array}{c}\mathbf{b} / \mathbf{c}=\mathbf{2 . 5} \\
\mathbf{E}=\mathbf{1 / 8}\end{array}$ & $\begin{array}{c}\mathbf{b} / \mathbf{c}=\mathbf{4} \\
\mathbf{E}=\mathbf{1 / 8}\end{array}$ & $\begin{array}{c}\mathbf{b} / \mathbf{c}=\mathbf{4} \\
\mathbf{E}=\mathbf{1} \mathbf{1 6}\end{array}$ & $\begin{array}{c}\mathbf{b} / \mathbf{c}=\mathbf{4} \\
\mathbf{E}=\mathbf{0}\end{array}$ \\
\hline Sessions per treatment & 3 & 2 & 3 & 4 & 3 & 3 \\
\hline Subjects per treatment & 72 & 52 & 64 & 90 & 58 & 48 \\
\hline $\begin{array}{l}\text { Average number of } \\
\text { interactions }\end{array}$ & 11 & 11.5 & 10.7 & 11.3 & 9.9 & 7.8 \\
\hline $\begin{array}{l}\text { Average number of } \\
\text { rounds per interaction }\end{array}$ & 8.4 & 8.3 & 8.3 & 8.1 & 8.0 & 8.2 \\
\hline
\end{tabular}

Following the end of the series of repeated prisoner's dilemmas, subjects played a dictator game and answered survey questions related to prosocial behavior, motivation, 
strategies and demographics (see Dreber, Fudenberg and Rand (2010) for more information).

\section{Theoretical and Experimental Background}

We begin by analyzing the set of equilibria of the various specifications. In all of the treatments, the only static equilibrium is to defect. In the treatment with $b / c=1.5$, the only Nash equilibrium is ALLD, while the other treatments all allow cooperative equilibria. ${ }^{16}$ As there are no explicit characterization theorems for the entire set of equilibrium outcomes for noisy repeated games with fixed discount factors, our initial analysis focused on a few repeated game strategies that have previously received attention.

In particular, we chose the payoffs so that when $\mathrm{b} / \mathrm{c}=4$, the memory- 1 strategy PTFT- "Play C if yesterday's outcome was (C,C) or (D,D) and otherwise play D" -is an equilibrium. This strategy has received a great deal of attention in the literature on evolutionary game theory, where it is called Win-Stay Loose-Shift (Nowak and Sigmund 1993; Wedekind and Milinski 1996; Martin Posch 1999; Imhof, Fudenberg and Nowak 2007). When both players use PTFT, one play of D (either intentionally or by mistake) leads to one round of (D,D) followed by a return to the equilibrium path; the strategy is called "perfect" because this error-correcting property allows it to be subgame-perfect, in contrast to TFT which typically is not. ${ }^{17}$ PTFT has theoretical appeal because it is errorcorrecting and has only memory 1 , but we conjecture that most subjects will view it as counterintuitive to cooperate after mutual defection, which raises the question of how widely the strategy is actually used.

Standard equilibrium analysis predicts no cooperation when $b / c=1.5$, but offers little guidance when $b / c$ is large enough that there are cooperative equilibria. The evolutionary game theory models of Nowak and Sigmund (1993) and Imhof, Fudenberg and Nowak (2007) predict cooperation when $\mathrm{b} / \mathrm{c}=4$, and moreover predict that subjects will play PTFT. Since these analyses restrict attention to strategies that base their

\footnotetext{
${ }^{16}$ Because the error term is strictly positive regardless of the actions played, every information set is reached with positive probability, and Nash equilibrium implies sequential rationality. Thus in the games with errors every Nash equilibrium is a sequential equilibrium, and every pure-strategy Nash equilibrium is equivalent to a perfect public equilibrium.

${ }^{17}$ In the game without errors, PTFT is a subgame-perfect equilibrium if $c<\delta(b-c)$ or $\delta>1 /(b / c-1)$ which is the case when $\mathrm{b} / \mathrm{c}=2.5$ or 4 . Analysis of the game with errors shows that PTFT is not an equilibrium when $\mathrm{b} / \mathrm{c}=2$ or 2.5 , essentially because the errors lower the expected value of cooperation, but PTFT is an equilibrium of the game with errors when $b / c=4$. See the online appendix for details.
} 
decisions only on the last round's outcome, however, they predict defection when $b / c=2$ or 2.5. The Fudenberg and Maskin $(1990,1994)$ evolutionary analysis of repeated games with vanishingly rare errors predicts cooperation in all three treatments with cooperative equilibria, but does not provide a precise prediction of what strategies will be played.

Experimental work on repeated games without errors also suggests that cooperation is more likely when it is more beneficial, and in particular that the existence of an cooperative equilibrium is necessary but not sufficient for there to be a substantial amount of cooperation (e.g., Alvin E. Roth and J. Keith Murnighan 1978; Murnighan and Roth 1983; Robert A. Feinberg and Thomas A. Husted 1993; Duffy and Ochs 2004; Dal Bó 2005; Dreber et al. 2008; Dal Bó and Frechette 2011; Matthias Blonski, Peter Ockenfels and Giancarlo Spagnolo 2011). Blonski and Spagnolo (2004) proposed that the key to whether cooperation occurs is whether TFT is a best response to a $1 / 2-1 / 2$ probability distribution over TFT and ALLD, i.e. whether TFT risk-dominates ALLD in the game with only those two strategies. ${ }^{18}$ Dal Bó and Frechette (2011) and Blonski, Ockenfels and Spagnolo (2011) find empirical support for this risk-dominance criterion in games without noise; and in a re-analysis of the no-noise experiments of Dreber et al. (2008), we find that the same criterion successfully predicts when cooperation is stable.

The success of the "risk dominance by TFT" criterion in experiments without noise raises the question of whether a similar criterion will explain cooperation in games with noise. One complication is that in our experiment, noise lowers the payoff of TFT against itself sufficiently that TFT is not an equilibrium of the overall game. ${ }^{19}$ It is however an equilibrium of the $2 \times 2$ game where players are restricted to play either TFT or ALLD; in this $2 \times 2$ game TFT is only risk dominant if $b / c=2.5$ or 4 . Thus to the extent that the risk-dominance criterion extends to games with noise, it predicts substantially more cooperation when $b / c=2.5$ than when $b / c=2$.

This combination of observations about equilibria of the game and insights from past experiments leads to our first set of experimental questions:

\footnotetext{
${ }^{18}$ This is the case when the present value of cooperation is sufficiently high compared to the loss caused by one period of (C,D). Note that Blonski, Ockenfels and Spagnolo (2011) offer an alternative theoretical justification for this equilibrium selection criterion.

${ }^{19}$ See the online appendix for TFT equilibrium calculations.
} 
QUESTION 1: Is cooperation more frequent in treatments where there are cooperative equilibria? Is risk dominance of TFT over ALLD a good predictor of cooperation?

QUESTION 2: Is there substantially more cooperation when cooperation is the outcome of an equilibrium in strategies which base their play on outcomes in the previous round?

The answers to questions 1 and 2 provide some indirect evidence on the strategies that subjects use. To get a more precise understanding of the particular strategies being employed by subjects, we examine more direct evidence on their play. This leads to our four additional experimental questions:

QUESTION 3: What strategies do subjects use in the noisy prisoner's dilemma? Do subjects use PTFT when it is an equilibrium strategy?

QUESTION 4: How do the strategies used vary with the gains to cooperation?

QUESTION 5: How do the strategies used vary with the level of noise?

\section{Methodology}

The general theory of repeated games, like that of extensive form games, views strategies as complete contingent plans, which specify how the player will act in every possible information state. In practice, cognitive constraints may lead subjects to use relatively simple strategies, corresponding to automata with a small number of internal states. However, it is unclear what a priori restrictions one should impose on subjects' strategies, and one of the goals of our experiment is to let the data reveal what sorts of strategies are actually used. For this reason we did not want to use the "strategy method," where subjects are asked to pick a strategy that is implemented for them: The full set of strategies is infinite, so forcing subjects to choose a strategy that depends only on the previous round's outcome (memory-1) is much too restrictive while allowing for all strategies that depend on the last two periods (memory-2) gives too large a strategy set to explicitly present. In addition, we would like to consider some simple strategies such as Grim, which can be viewed as a two-state automata but has arbitrarily long memory, as its current play depends on whether "D" was played in any previous round. As the data 
cannot discriminate between all possible repeated game strategies, we used a combination of prior intuition, survey responses and data analysis to identify a small set of strategies that seem to best describe actual play.

There has been comparatively little past work on identifying the strategies subjects use in repeated game experiments. In the repeated prisoner's dilemma, Wedekind and Milinski (1996) note that subjects rarely play C in the round after they played D and the opponent played C, and take this as evidence of PTFT, but since subjects rarely played $\mathrm{C}$ following $(\mathrm{D}, \mathrm{D})$, their data seems more consistent with some sort of grim strategy. Dal Bó and Frechette (2011) used maximum likelihood to estimate the proportions of subjects using one of six ex-ante relevant strategies. They find that ALLD and TFT account for the majority of their data. Aoyagi and Frechette (2009) study experimental play of a prisoner's dilemma where subjects do not observe their partner's actions but instead observe a noisy symmetric signal of it. The signal is a real number, and has the same distribution under $(C, D)$ and $(D, C)$, so that commonly discussed prisoner's dilemma strategies such as TFT are not implementable. They find that subjects play "trigger strategies" of memory 1, except in the limit no-noise case where signals from two rounds ago also have an impact. Engle-Warnick and Slonim (2006) study the strategies used in a repeated sequential-move trust game by counting how many observations of a subject's play in a given interaction is exactly described by a given strategy. They find that in most of the interactions, the investors choose actions which are consistent with a grim trigger strategy, while the play of the trustees is more diverse. Gabriele Camera, Marco Casari and Maria Bigoni (2010) on the other hand find little evidence of grim trigger strategies on the subject level when subjects are randomly put in groups of four to play an indefinitely repeated PD where in each round they are randomly matched with one subject in the group. Even though behavior at the aggregate looks like grim trigger, individual behavior is far more heterogeneous.

An advantage of studying repeated games with errors is that we can more easily identify different strategies: In the absence of errors a number of repeated game strategies are observationally equivalent, for example if a pair of subjects cooperates with each other in every round, we see no data on how they would have responded to defections. Thus the introduction of errors has a methodological advantage as well as a substantive one, as the errors will lead more histories to occur and thus make it easier to distinguish between histories. 
To have any hope of inferring the subjects' strategies from their play, we must focus our attention on a subset of the infinitely many repeated game strategies. We begin with strategies that have received particular attention in the theoretical literature: ALLD, ALLC, Grim ${ }^{20}$, TFT, and PTFT. Because one round of punishment is only enough to sustain cooperation in one of our four treatments (when $b / c=4$ ) we also include modifications of TFT and PTFT that react to D with two rounds of defection, we call these 2TFT and 2PTFT. We also include the strategy T2 used by Dal Bó and Frechette $(2011)^{21}$

To inform our extension of this strategy set, we asked subjects to describe their strategies in a post-experimental survey. Several regularities emerged from these descriptions. Many subjects reported 'giving the benefit of the doubt' to an opponent on the first defection, assuming that it was a result of noise rather than purposeful malfeasance; only after two or three defections by their partner would they switch to defection themselves. ${ }^{22}$ We refer to this slow-to-anger behavior as 'leniency'. None of the strategies mentioned above are lenient; note that leniency requires looking further into the past than permitted by memory-1 strategies. Subjects also varied in the extent to which they reported being willing to return to cooperation following a partner's defection. We refer to this strategic feature as 'forgiveness', which is an often-discussed aspect of TFT (as opposed to Grim, for example); 2TFT also shows forgiveness, as do PTFT and 2PTFT, although only following mutual defection.

In response to the subjects' strategy descriptions, we added several lenient strategies to our analysis. Because our games were on average only 8 rounds in length, we have limited power to explore intermediate levels of forgiveness between TFT and Grim, so we restrict strategies to either forgive after 1 to 3 rounds or to never forgive (as with Grim and its lenient variants). ${ }^{23}$

\footnotetext{
${ }^{20}$ As in Dal Bó \& Frechette (2011), our specification of Grim begins by playing C and then switches permanently to $\mathrm{D}$ as soon as either player defects.

${ }^{21}$ 2TFT initially plays $\mathrm{C}$, then afterwards plays $\mathrm{C}$ if opponent has never played $\mathrm{D}$ or if the opponent played $\mathrm{C}$ in both of the previous two rounds. A defection by the partner triggers two rounds of punishment defection in both 2TFT and T2. However, T2 automatically returns to $\mathrm{C}$ following the two Ds, regardless of the partner's play during this time, while 2TFT only returns to $\mathrm{C}$ if the partner played C in both of the "punishment rounds." Additionally, T2 begins its punishment if either player defects, whereas 2TFT responds only to the partner's defection.

${ }^{22}$ Subjects' free-response descriptions of their strategies are reproduced in the online appendix.

${ }^{23}$ More generally the average length of 8 interactions imposes restrictions on our ability to estimate the extent to which subjects condition on long histories. This constraint reflects a tradeoff between our interest in the way subjects use past history and our desire to limit sessions to 90 minutes (to avoid fatiguing the
} 
As strategies that are both lenient and forgiving, we include TFT variants that switch to defection only after the other player chooses D multiple times in a row, considering TF2T (plays D if the partner's last two moves were both D) and TF3T (plays $\mathrm{D}$ if the partner's last three moves were D). For strategies that are lenient but not forgiving, we include Grim variants that wait for multiple rounds of D (by either player) before switching permanently to defection, considering Grim2 (waits for two consecutive rounds in which either player played D) and Grim3 (waits for three consecutive D rounds). We include three strategies that punish twice (intermediate to TFT's one round of punishment and Grim's unending punishment) but can be implemented by conditioning only on the last 3 rounds. These are T2 and 2TFT, which were discussed above, and 2TF2T ("2 Tits for 2 Tats"), which waits for the partner to play D twice in a row, and then punishes by playing D twice in a row. Because we do not include strategies that punish for a finite number of rounds greater than two, our estimated share of "Grim" strategies may include some subjects who use such strategies with more than two rounds of punishment.

Other subjects indicated that they used strategies which tried to take advantage of the leniency of others by defecting initially and then switching to cooperation. Thus we consider 'exploitive' versions of our main cooperative strategies that defect on the first move and then return to the strategy as normally specified: D-TFT ${ }^{24}$, D-TF2T, D-TF3T, D-Grim2 and D-Grim3. ${ }^{25}$ Because TF2T appears prevalent in many treatments, we also looked at whether subjects used the strategy that alternates between D and C (DC-Alt), as this strategy exploits the leniency and forgiveness of TF2T. Lastly, some subjects reported playing strategies which give the first impression of being cooperative and then switch to defection, hoping the partner will assume the subsequent Ds are due to error. Therefore we include a strategy which plays $\mathrm{C}$ in the first round and D thereafter (C-toALLD). Each strategy is described verbally in Table 2; complete descriptions are given in the online appendix.

subjects) while allowing them to play enough interactions to have some chance to learn. Fortunately the average length of 8 was enough to provide convincing evidence that subjects can use forgiving strategies with memory greater than 1 .

${ }^{24}$ Boyd and Jeffrey P. Lorberbaum (1987) call this strategy "Suspicious Tit for Tat."

${ }^{25}$ ALLD and D-Grim are identical except when the other player plays $\mathrm{C}$ in the first round, and you mistakenly also play $\mathrm{C}$ in the first round: here D-Grim cooperates while ALLD defects. Thus we do not include D-Grim in our analysis as we do not have sufficient number of observations per subject to differentiate between the two. 
Table 2. Descriptions of the 20 strategies considered.

\begin{tabular}{|c|c|c|}
\hline Strategy & Abbreviation & Description \\
\hline Always Cooperate & ALLC & Always play $\mathrm{C}$ \\
\hline Tit-for-Tat & TFT & Play C unless partner played D last round \\
\hline Tit-for-2-Tats & TF2T & $\begin{array}{l}\text { Play } \mathrm{C} \text { unless partner played } \mathrm{D} \text { in both of the } \\
\text { last } 2 \text { rounds }\end{array}$ \\
\hline Tit-for-3-Tats & TF3T & $\begin{array}{l}\text { Play } \mathrm{C} \text { unless partner played } \mathrm{D} \text { in all of the } \\
\text { last } 3 \text { rounds }\end{array}$ \\
\hline 2-Tits-for-1-Tat & $2 \mathrm{TFT}$ & $\begin{array}{l}\text { Play } C \text { unless partner played D in either of } \\
\text { the last } 2 \text { rounds ( } 2 \text { rounds of punishment if } \\
\text { partner plays D) }\end{array}$ \\
\hline 2-Tits-for-2-Tats & 2TF2T & $\begin{array}{l}\text { Play C unless partner played } 2 \text { consecutive } \\
\text { Ds in the last } 3 \text { rounds ( } 2 \text { rounds of } \\
\text { punishment if partner plays D twice in a row) }\end{array}$ \\
\hline $\mathrm{T} 2$ & $\mathrm{~T} 2$ & $\begin{array}{l}\text { Play C until either player plays D, then play } \\
\mathrm{D} \text { twice and return to } \mathrm{C} \text { (regardless of all } \\
\text { actions during the punishment rounds) }\end{array}$ \\
\hline Grim & Grim & $\begin{array}{l}\text { Play } \mathrm{C} \text { until either player plays } \mathrm{D} \text {, then play } \\
\text { D forever }\end{array}$ \\
\hline Lenient Grim 2 & Grim2 & $\begin{array}{l}\text { Play } C \text { until } 2 \text { consecutive rounds occur in } \\
\text { which either player played } D \text {, then play D } \\
\text { forever }\end{array}$ \\
\hline Lenient Grim 3 & Grim3 & $\begin{array}{l}\text { Play } C \text { until } 3 \text { consecutive rounds occur in } \\
\text { which either player played } D \text {, then play D } \\
\text { forever }\end{array}$ \\
\hline $\begin{array}{l}\text { Perfect Tit-for-Tat / Win-Stay- } \\
\text { Lose-Shift }\end{array}$ & PTFT & $\begin{array}{l}\text { Play C if both players chose the same move } \\
\text { last round, otherwise play D }\end{array}$ \\
\hline $\begin{array}{l}\text { Perfect Tit-for-Tat with } 2 \\
\text { rounds of punishment }\end{array}$ & 2PTFT & $\begin{array}{l}\text { Play C if both players played C in the last } 2 \\
\text { rounds, both players played D in the last } 2 \\
\text { rounds, or both players played D } 2 \text { rounds } \\
\text { ago and C last round. Otherwise play D }\end{array}$ \\
\hline Always Defect & ALLD & Always play D \\
\hline False cooperator & C-to-ALLD & Play C in the first round, then D forever \\
\hline Exploitive Tit-for-Tat & D-TFT & Play D in the first round, then play TFT \\
\hline Exploitive Tit-for-2-Tats & D-TF2T & Play D in the first round, then play TF2T \\
\hline Exploitive Tit-for-3-Tats & D-TF3T & Play D in the first round, then play TF3T \\
\hline Exploitive Grim2 & D-Grim2 & Play D in the first round, then play Grim2 \\
\hline Exploitive Grim3 & D-Grim3 & Play D in the first round, then play Grim3 \\
\hline Alternator & DC-Alt & Start with $\mathrm{D}$, then alternate between $\mathrm{C}$ and D \\
\hline
\end{tabular}

To assess the prevalence of each strategy in our data, we follow Dal Bó and Frechette (2011) and suppose that each subject chooses a fixed strategy at the beginning of the session (or alternatively for the last four interactions, when we restrict attention to 
those observations) ${ }^{26}$, and moreover that in addition to the extrinsically imposed execution error, subjects make mistakes when choosing their intended action, so every sequence of choices (e.g. of intended actions) has positive probability. ${ }^{27}$ More specifically, we suppose that if subject $i$ uses strategy $s$, her chosen action in round $r$ of interaction $k$ is $\mathrm{C}$ if $s_{i k r}(s)+\gamma \boldsymbol{\varepsilon}_{i k r} \geq 0$, where $s_{i k r}(s)=1$ if strategy $s$ says to play $\mathrm{C}$ in round $r$ of interaction $k$ given the history to that point, and $s_{i k r}(s)=-1$ if $s$ says to play D. Here $\varepsilon_{i k r}$ is an error term that is independent across subjects, rounds, interactions, and histories, $\gamma$ parameterizes the probability of mistakes, and the density of the error term is such that the overall likelihood that subject $i$ uses strategy $s$ is

$$
p_{i}(s)=\Pi_{k} \Pi_{r}\left(\frac{1}{1+\exp \left(-s_{i k r}(s) / \gamma\right)}\right)^{y_{i k r}}\left(\frac{1}{1+\exp \left(s_{i k r}(s) / \gamma\right)}\right)^{1-y_{i k r}},
$$

where $y_{i k r}$ is 1 if the subject chose $\mathrm{C}$ and 0 if the subject chose D. ${ }^{28}$

To better understand the mechanics of the specification, suppose that an interaction lasts $w$ rounds, that in the first round the subject chose $\mathrm{C}$, the first round outcome was that the subject played $\mathrm{C}$ and her partner played $\mathrm{D}$, and in the second round the subject chose D. Then for strategy $s=$ TFT, which plays C in the first round, and plays D in the second round following (C,D), the likelihood of the subject's play is the probability of two "no-error" draws. This is the same probability that we would assign to the overall sequence of the subject's play given the play of the opponent - it makes no difference whether we compute the likelihood round by round or for the whole interaction.

For any given set of strategies $\mathrm{S}$ and proportions $\mathrm{p}$, we then derive the likelihood for the entire sample, namely $\sum_{I} \ln \left(\sum_{s \in S} p(s) p_{i}(s)\right)$. Note that the specification assumes that all subjects are ex-ante identical with the same probability distribution over

\footnotetext{
${ }^{26}$ We found that conducting the MLE supposing that subjects pick a fixed strategy at the beginning of each interaction, as opposed to using the same strategy throughout the session, gave qualitatively similar results to those presented below.

${ }^{27}$ Recall that we, unlike our subjects, observe the intended actions as well as the implemented ones. We use this more informative data in our estimates.

${ }^{28}$ Thus the probability of an error in implementing one's strategy is $1 /(1+\exp (1 / \gamma))$. Note that this represents error in intention, rather than the experimentally imposed error in execution. This formulation assumes that all strategies have an equal rate of implementation error. In the online appendix we show that the MLE estimates of strategy shares are robust to allowing each strategy have a different value of $\gamma$.
} 
strategies and the same distribution over errors; one could relax this at the cost of adding more parameters. Because $p$ describes a distribution over strategies, this likelihood function implies that in a very large sample we expect fraction $p(s)$ of subjects to use strategy s, though for finite samples there will be a non-zero variance in the population shares. We use maximum likelihood estimation (MLE) to estimate the prevalence of the various strategies, and bootstrapping to associate standard errors with each of our frequency estimates. We construct 100 bootstrap samples for each treatment by randomly sampling the appropriate number of subjects with replacement. We then determine the standard deviation of the MLE estimates for each strategy frequency across the 100 bootstrap samples.

To investigate the validity of this estimation procedure, we tested it on simulated data. For a given strategy frequency distribution, we assigned strategies to 3 groups of 20 computer agents. We then generated a simulated history of play across 4 interactions by randomly pairing members of each group to play games with representative lengths from the game length sequence used in the experiment $\left(t_{1}=5, t_{2}=11, t_{3}=8, t_{4}=9\right)$. As in the main experimental treatments, we included a $1 / 8$ probability of error, and recorded both the intended and actual action of each agent. We generated simulated data in this way using strategy distributions similar to those estimated from the experimental data (see Table 3), and then used the MLE method described above to estimate the strategy frequencies. The MLE results were consistent with the actual strategy frequencies, giving us confidence in the estimation procedure. ${ }^{29}$

\section{Results}

We begin by examining behavior in the 4 treatments with $\mathrm{E}=1 / 8$; we will then compare this to the behavior in the controls with $\mathrm{E}=0$ and $\mathrm{E}=1 / 16$ using $\mathrm{b} / \mathrm{c}=4$, which is the ratio most favorable to cooperation.

Examining play in the first round of each interaction, as displayed in Figure 2, suggests that there was some learning, except perhaps when $b / c=1.5$; this is confirmed by the statistical analysis reported in Appendix B. To reduce the potential effects of learning while striking a balance with the need for data, our analysis will focus on how subjects

${ }^{29}$ See Appendix A for MLE results using simulated data. 
played in the last four interactions of the session, which is roughly the last third of each session. ${ }^{30}$

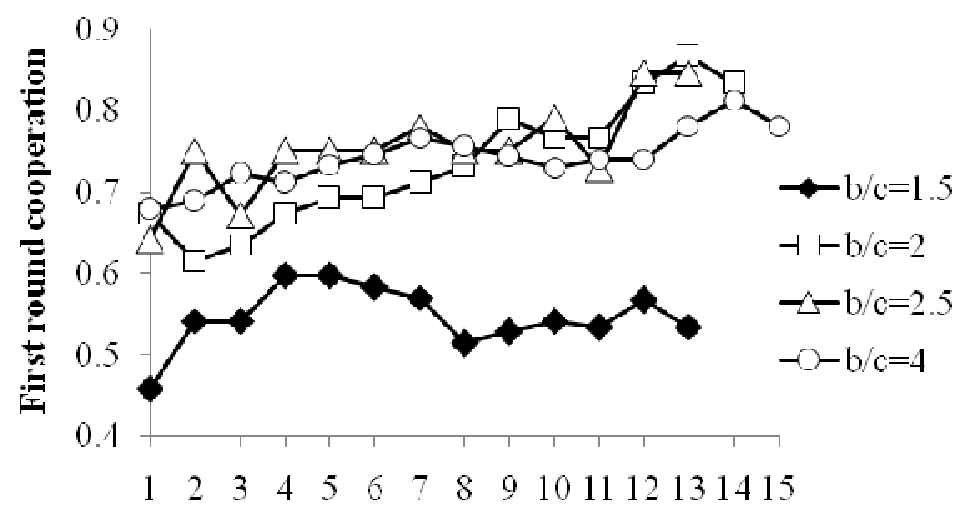

Interaction

Figure 2. First round cooperation over the course of the session, by payoff specification.

QUESTION 1: Is cooperation more frequent in treatments where there are cooperative equilibria? Is risk dominance of TFT over ALLD a good predictor of cooperation?

Figure 3 reports both cooperation in the first round of the last 4 interactions and the average cooperation over the last 4 interactions as a whole, which can depend on the relationship between the two subjects' strategies and also on possible random errors. ${ }^{31}$ We see that there is markedly less cooperation when $b / c=1.5$, both in the first round $(1.5$ vs. $2, \mathrm{p}=0.016 ; 1.5$ vs. $2.5, \mathrm{p}=0.003 ; 1.5$ vs. $4, \mathrm{p}=0.004)$ and overall ( 1.5 vs. $2, \mathrm{p}=0.001$; 1.5 vs. $2.5, \mathrm{p}<0.001 ; 1.5$ vs. $4, \mathrm{p}<0.001)$. Conversely, we see little difference in first round cooperation between the three treatments with cooperative equilibria ( 2 vs. 2.5 , $\mathrm{p}=0.71 ; 2$ vs. $4, \mathrm{p}=0.83 ; 2.5$ vs. $4, \mathrm{p}=0.87$ ); and while there is an increase in overall cooperation going from $b / c=2$ to $b / c=2.5$, this increase is smaller than that between $b / c=1.5$ and $b / c=2$ and is only marginally significant $(p=0.058)$. Moreover there is no significant difference in overall cooperation between $b / c=2.5$ and $b / c=4(p=0.73)$. The reason there is about the same amount of initial cooperation in $b / c=2$ and 2.5 yet somewhat more overall cooperation in the latter case seems related to the fact that more subjects are more forgiving in the latter treatment, as seen in the discussion of Questions

\footnotetext{
${ }^{30}$ Our results are not sensitive to this particular cutoff. Using either the last 6 or last 2 interactions instead yields very similar results. See the online appendix for details.

${ }^{31}$ For each pairwise b/c comparison, we report the results of a logistic regression over first-round/all individual decisions, with a b/c value dummy as the independent variable, clustered on both subject and interaction pair.
} 
3-4. Because the largest difference in cooperation occurs between $b / c=1 / 5$ and $b / c=2$, as opposed to between $b / c=2$ and $b / c=2.5$, the data do not show the strong support for risk dominance of TFT as the key determinant of the level of cooperation in games with noise that was seen in studies of games without noise.

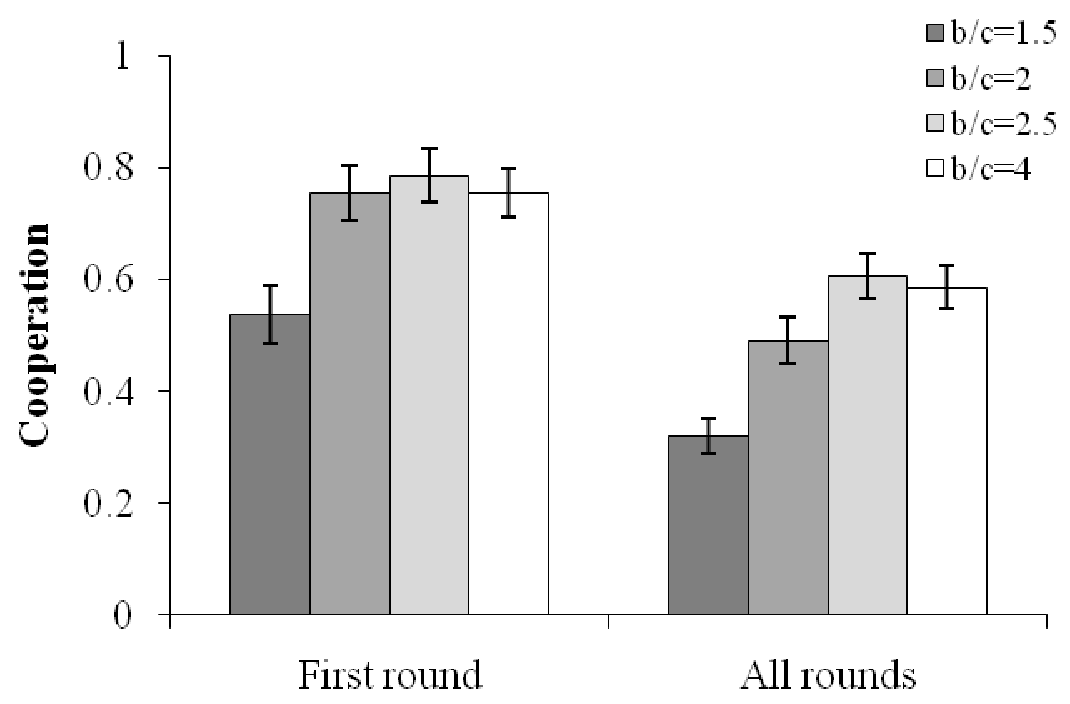

Figure 3. First round and overall cooperation by payoff specification, averaged over the last 4 interactions of each session. See Table 4 for a list of the cooperation frequencies displayed here. Error bars indicate standard error of the mean, clustered on subject and interaction pair.

QUESTION 2: Is there substantially more cooperation when cooperation is the outcome of an equilibrium in strategies which base their play on outcomes in previous round?

Indeed, we see a substantial amount of cooperation when $b / c=2$ and 2.5 , even though cooperative equilibria in these treatments require memory 2 or more. ${ }^{32}$ To the extent that play resembles an equilibrium of the repeated game, these results are a first sign that the predictions of the memory- 1 restriction are not consistent with the data.

QUESTION 3: What strategies do subjects use in the noisy prisoner's dilemma? Do subjects use PTFT when it is an equilibrium strategy?

\footnotetext{
${ }^{32}$ This theoretical result is robust to considering memory- 1 strategies which forget the state with some nonzero probability. Regardless of the probability of forgetting, TFT and PTFT are not equilibria at E=1/8 and $\mathrm{b} / \mathrm{c}=2$ or $\mathrm{b} / \mathrm{c}=2.5$. See the online appendix for further discussion.
} 
We now report the results of the MLE analysis of strategy choice, examining the last 4 interactions of each session. ${ }^{33}$ We consider 20 strategies in total (Table 2): the fully cooperative strategies ALLC, TFT, TF2T, TF3T, 2TFT, 2TF2T, Grim, Grim2, Grim3, PTFT, 2PTFT and T2, which always play $\mathrm{C}$ against themselves in the absence of errors; the fully non-cooperative strategies ALLD and D-TFT, which always play D against themselves in the absence of errors; and the partially cooperative strategies C-to-ALLD, D-TF2T, D-TF3T, D-Grim2, D-Grim3 and DC-Alt, which play a combination of C and D against themselves in the absence of error. ${ }^{34}$ Of these, only 11 are present at frequencies significantly greater than 0 in at least one payoff specification: the cooperative strategies ALLC, TFT, TF2T, TF3T, 2TFT, 2TF2T, Grim, Grim2 and Grim3, and the noncooperative strategies ALLD and D-TFT. ${ }^{35}$

Thus we restrict our attention to these 11 strategies (Table 3). We do not find any evidence of subjects using PTFT in any payoff specification - PTFT never received a positive weight in any of the bootstrapped samples. In the treatments with cooperative equilibria, the most common cooperative strategies TF2T, TF3T, Grim2 and Grim3 are all lenient.

\footnotetext{
${ }^{33}$ Analysis of simulated data suggests that MLE on 4 interactions lasting on average 8 rounds detects strategies whose frequencies are 5\% or higher, but that lower-frequency strategies may not be detected.

${ }^{34}$ Following Dal Bo and Frechette, we consider only pure strategies in the MLE estimation. The evolutionary game theory literature suggests the consideration of "generous tit-for-tat" or GTFT (Nowak and Sigmund 1990), which cooperates with probability strictly between 0 and 1 if the partner defected last period, and otherwise cooperates. Simulations show that this strategy will be identified by our estimation as playing TF3T, but that expanding our MLE procedure to include stochastic strategies can differentiate GTFT from TF3T. Doing so suggests that the majority of leniency observed in our data is not in fact the result of stochastic memory-1 strategies, but is rather due to lenient strategies with longer memories. The online appendix reports these results, which should be viewed as a first step towards understanding how to test for mixed strategies; we hope to explore the issues posed by mixed strategies in greater detail in future work.

${ }^{35}$ See Appendix C for the estimates and standard errors for the full set of 20 strategies. At the request of the referees, we also explored versions of TFT and PTFT which forget the state with some non-zero probability, versions of TFT and Grim which ignore a defection in the first round, and a family of strategies which cooperate until the fraction of D by their partner passes some threshold. None of these strategies were present at frequencies significantly greater than 0 . See the online appendix for the details of these robustness checks.
} 
Table 3. Maximum likelihood estimates using the last 4 interactions of each session. All payoff specifications use error rate $E=1 / 8$. Bootstrapped standard errors (shown in parentheses) used to calculate p-values.

$\dagger$ Significant at $p<0.1$, * Significant at $p<0.05$, ** Significant at $p<0.01$.

\begin{tabular}{|c|c|c|c|c|}
\hline & $\mathrm{b} / \mathrm{c}=1.5$ & $b / c=2$ & $\mathrm{~b} / \mathrm{c}=2.5$ & $\mathrm{~b} / \mathrm{c}=4$ \\
\hline ALLC & $\begin{array}{c}0 \\
(0)\end{array}$ & $\begin{array}{c}0.03 \\
(0.03) \\
\end{array}$ & $\begin{array}{c}0 \\
(0.02) \\
\end{array}$ & $\begin{array}{l}0.06 \dagger \\
(0.03)\end{array}$ \\
\hline TFT & $\begin{array}{c}0.19 * * \\
(0.05)\end{array}$ & $\begin{array}{c}0.06 \\
(0.04) \\
\end{array}$ & $\begin{array}{l}0.09 * \\
(0.04) \\
\end{array}$ & $\begin{array}{c}0.07 * \\
(0.03) \\
\end{array}$ \\
\hline TF2T & $\begin{array}{c}0.05 \\
(0.03) \\
\end{array}$ & $\begin{array}{c}0 \\
(0)\end{array}$ & $\begin{array}{l}0.17^{*} \\
(0.06)\end{array}$ & $\begin{array}{c}0.20 * * \\
(0.07)\end{array}$ \\
\hline TF3T & $\begin{array}{c}0.01 \\
(0.01)\end{array}$ & $\begin{array}{c}0.03 \\
(0.03) \\
\end{array}$ & $\begin{array}{c}0.05 \\
(0.05)\end{array}$ & $\begin{array}{l}0.09 * \\
(0.04)\end{array}$ \\
\hline 2TFT & $\begin{array}{c}0.06 \\
(0.04) \\
\end{array}$ & $\begin{array}{l}0.07 \dagger \\
(0.04)\end{array}$ & $\begin{array}{c}0.02 \\
(0.02) \\
\end{array}$ & $\begin{array}{c}0.03 \\
(0.02) \\
\end{array}$ \\
\hline 2TF2T & $\begin{array}{c}0 \\
(0.02) \\
\end{array}$ & $\begin{array}{l}0.11 * \\
(0.05) \\
\end{array}$ & $\begin{array}{l}0.11 \dagger \\
(0.06)\end{array}$ & $\begin{array}{l}0.12 * \\
(0.05)\end{array}$ \\
\hline Grim & $\begin{array}{c}0.14 * * \\
(0.04)\end{array}$ & $\begin{array}{c}0.07 \\
(0.05) \\
\end{array}$ & $\begin{array}{l}0.11 * \\
(0.04) \\
\end{array}$ & $\begin{array}{l}0.04 \dagger \\
(0.02) \\
\end{array}$ \\
\hline Grim2 & $\begin{array}{l}0.06 \dagger \\
(0.03)\end{array}$ & $\begin{array}{c}0.18 * * \\
(0.06)\end{array}$ & $\begin{array}{c}0.02 \\
(0.03) \\
\end{array}$ & $\begin{array}{l}0.05 \dagger \\
(0.03)\end{array}$ \\
\hline Grim3 & $\begin{array}{c}0.06 \\
(0.03) \\
\end{array}$ & $\begin{array}{c}0.28 * * \\
(0.08) \\
\end{array}$ & $\begin{array}{c}0.24 * * \\
(0.07) \\
\end{array}$ & $\begin{array}{c}0.11 * * \\
(0.04) \\
\end{array}$ \\
\hline ALLD & $\begin{array}{c}0.29 * * \\
(0.06)\end{array}$ & $\begin{array}{c}0.17 * * \\
(0.06) \\
\end{array}$ & $\begin{array}{c}0.14 * * \\
(0.04)\end{array}$ & $\begin{array}{c}0.23^{* *} \\
(0.04) \\
\end{array}$ \\
\hline D-TFT & $\begin{array}{c}0.14 * * \\
(0.05)\end{array}$ & $\begin{array}{c}0 \\
(0)\end{array}$ & $\begin{array}{l}0.05 \dagger \\
(0.03)\end{array}$ & $\begin{array}{c}0 \\
(0)\end{array}$ \\
\hline Gamma & $\begin{array}{c}0.46 * * \\
(0.02)\end{array}$ & $\begin{array}{l}0.5^{* * *} \\
(0.03)\end{array}$ & $\begin{array}{c}0.49 * * \\
(0.03)\end{array}$ & $\begin{array}{c}0.43 * * \\
(0.02)\end{array}$ \\
\hline
\end{tabular}

Note that in all treatments the MLE assigns a substantial share to strategies that depend on outcomes from more than one period ago. To provide additional evidence for this conclusion, we use a logistic regression to test whether subjects condition play on their partner's decision two rounds ago. Bias introduced by heterogeneity presents a potential challenge for this approach: the other's play two rounds ago interacts with own play two rounds ago to determine the history in the previous round, so other's play two rounds ago could have a spuriously significant coefficient in a heterogeneous population of subjects all of whom use memory 1 strategies. To control for bias introduced by heterogeneity, we include controls for the type of the player making the decision, as in 
Aoyagi \& Frechette (2009). ${ }^{36}$ We conduct a logistic regression with correlated random effects, regressing own decision in round t against own play in round $t-1$, other's play in $\mathrm{t}$ 1 , own play in $\mathrm{t}-2$ and other's play in $\mathrm{t}-2$, and including controls for $\mathrm{b} / \mathrm{c}$ ratio and own average frequency of first round cooperation and overall cooperation, both over the last 4 interactions. ${ }^{37}$ Consistent with the use of longer memories, we find a significant effect of other's play two rounds ago $(\operatorname{coeff}=1.01, \mathrm{p}<0.001)$. This result supports the conclusion that many subjects are conditioning on more than only the last round.

QUESTION 4: How do the strategies used vary with the gains to cooperation?

The strategies employed by subjects clearly vary according to the gains from cooperation. This can be seen from descriptive statistics analyzing aggregate behavior as well as from the MLE analysis, both of which are summarized in Table 4. Three trends are apparent.

First, cooperation is significantly lower at $b / c=1.5$ than at the higher $b / c$ ratios, as shown in Table 4 and visualized in Figure 3. Consistent with this observation, Table 4 also shows that the share of the non-cooperative strategies ALLD and D-TFT is $43 \%$ when $b / c=1.5$, which is substantially and significantly higher than in other $b / c$ conditions $(\mathrm{b} / \mathrm{c}=2,17 \%, \mathrm{p}<0.001 ; \mathrm{b} / \mathrm{c}=2.5,19 \%, \mathrm{p}<0.001 ; \mathrm{b} / \mathrm{c}=4,23 \%, \mathrm{p}=0.001){ }^{38}$

Second, leniency also increases when moving from $b / c=1.5$ to the higher $b / c$ ratios. To get a measure of leniency distinct from the MLE estimates, we examine all histories in which both subjects played $\mathrm{C}$ in all but the previous round, while in the previous round one subject played D. ${ }^{39}$ We then ask how frequently the subject who had hitherto cooperated showed leniency by continuing to cooperate despite the partner's

\footnotetext{
${ }^{36}$ For a general treatment of the topic, see Gary Chamberlain (1980) and James J. Heckman (1981).

${ }^{37}$ When we simulate data for various combinations of memory-1 strategies, we find that this regression returns a significant coefficient on partner's action in t-2 no more often than predicted by chance. We also find that when simulating only memory-1 strategies, the size of the estimated coefficient of play two rounds ago is at least an order of magnitude smaller than the coefficients for play last round, in contrast to the estimates on the experimental data; see the online appendix for a detailed discussion of these issues. Note that as the regression conditions on play two rounds ago, it necessarily omits decisions made in the first two rounds of each interaction.

${ }^{38}$ For each pairwise comparison of aggregated MLE coefficients, we report the results of a two-sample ttest using bootstrapped standard errors of the aggregated coefficients.

${ }^{39}$ We also include second round decisions in which the first round's outcome was CD.
} 
defection. ${ }^{40}$ At $\mathrm{b} / \mathrm{c}=1.5,17 \%$ of histories show leniency, compared to the significantly higher values of $63 \%$ at $b / c=2(b / c=1.5$ vs. $b / c=2, p=0.001), 67 \%$ at $b / c=2.5(b / c=1.5$ vs. $\mathrm{b} / \mathrm{c}=2.5, \mathrm{p}<0.001)$ and $66 \%$ at $\mathrm{b} / \mathrm{c}=4(\mathrm{~b} / \mathrm{c}=1.5$ vs. $\mathrm{b} / \mathrm{c}=4, \mathrm{p}<0.001)$. No significant difference in leniency exists among the higher $b / c$ ratios ( $>0.20$ for all comparisons). Thus leniency increases across the transition from $b / c=1.5$ to $b / c=2$. Analyzing strategy frequencies paints a similar picture. The combined frequency of the lenient strategies ALLC, TF2T, TF3T, 2TF2T, Grim2 and Grim3 is $18 \%$ at $\mathrm{b} / \mathrm{c}=1.5$ which is significantly less than at $\mathrm{b} / \mathrm{c}=2(62 \%, \mathrm{p}<0.001), \mathrm{b} / \mathrm{c}=2.5(60 \%, \mathrm{p}<0.001)$ or $\mathrm{b} / \mathrm{c}=4(63 \%, \mathrm{p}<0.001)$.

Table 4. Descriptive statistics of aggregate behavior, as well as aggregated MLE frequencies from Table 3. All specifications use E=1/8. The descriptive statistics for leniency and forgiveness are defined in the text. For MLE aggregation, all strategies other than ALLD and D-TFT are cooperative; lenient strategies are TF2T, TF3T, 2TF2T, Grim2 and Grim3; and forgiving strategies are TFT, TF2T, TF3T, 2TFT and 2TF2T.

\begin{tabular}{|c|c|c|c|c|}
\hline & $\mathrm{b} / \mathrm{c}=1.5$ & $\mathrm{~b} / \mathrm{c}=2$ & $\mathrm{~b} / \mathrm{c}=2.5$ & $\mathrm{~b} / \mathrm{c}=4$ \\
\hline \multicolumn{5}{|c|}{ Descriptive statistics } \\
\hline$\%$ C First Round & $54 \%$ & $75 \%$ & $79 \%$ & $76 \%$ \\
\hline$\%$ C All Rounds & $32 \%$ & $49 \%$ & $61 \%$ & $59 \%$ \\
\hline Leniency & $29 \%$ & $63 \%$ & $67 \%$ & $66 \%$ \\
\hline Forgiveness & $15 \%$ & $18 \%$ & $33 \%$ & $32 \%$ \\
\hline \multicolumn{5}{|c|}{ MLE aggregation } \\
\hline Cooperative strategies & $57 \%$ & $83 \%$ & $81 \%$ & $77 \%$ \\
\hline Lenient strategies & $18 \%$ & $62 \%$ & $60 \%$ & $63 \%$ \\
\hline Forgiving strategies & $31 \%$ & $29 \%$ & $44 \%$ & $57 \%$ \\
\hline
\end{tabular}

The gains to cooperation also influence the frequency of forgiveness. Forgiveness is more complicated to define and measure, as it describes a more complex pattern of behavior: to us it means that the players were initially cooperating, that one of them then defects leading the other player to "punish" the initial defector, and finally that the punishing player relents and returns to cooperation. To develop an operational measure of histories where forgiveness occurs, we first identify all histories in which (i) at least one subject chose $\mathrm{C}$ in the first round, (ii) in at least one previous round, the initially cooperative subject chose $\mathrm{C}$ while the other subject chose $\mathrm{D}$ and (iii) in the immediately

\footnotetext{
${ }^{40}$ For each pairwise b/c comparison of aggregate descriptive statistics, we report the results of a logistic regression over all decisions in lenient/forgiving histories, with a b/c dummy as the independent variable, clustered on both subject and interaction pair.
} 
previous round the formerly cooperative subject played D. We then ask how frequently this formerly cooperative subject showed forgiveness by returning to C. For example, if the outcome in the first round is (C,D), and the first player plays D in the second round, and $\mathrm{C}$ in the third, we would say that the first player had "forgiven" the second player. We find significantly less forgiveness at $b / c=1.5(15 \%)$ and $b / c=2(18 \%)$ compared to $\mathrm{b} / \mathrm{c}=2.5(33 \%)$ and $\mathrm{b} / \mathrm{c}=4(32 \%)(1.5$ vs. $2.5, \mathrm{p}<0.001 ; 1.5$ vs. $4, \mathrm{p}<0.001 ; 2$ vs. 2.5 , $\mathrm{p}=0.008 ; 2$ vs. $4, \mathrm{p}=0.007)$. Thus forgiveness increases significantly when $\mathrm{b} / \mathrm{c}$ increases from 2 to 2.5. This is again confirmed by examining strategy frequencies in the payoff specifications that support cooperation. The forgiving strategies ALLC, TFT, TF2T, TF3T, 2TFT and 2TF2T are less common at b/c=1.5 (31\%) and b/c=2 (29\%) than at $\mathrm{b} / \mathrm{c}=2.5(44 \%)$ and $\mathrm{b} / \mathrm{c}=4(57 \%)(1.5$ vs. $2.5, \mathrm{p}=0.061 ; 1.5$ vs. $4, \mathrm{p}<0.001 ; 2$ vs. 2.5 , $\mathrm{p}=0.054 ; 2$ vs. $4, \mathrm{p}<0.001 ; 2.5$ vs. $4, \mathrm{p}=0.054)$.

QUESTION 5: How do the strategies used vary with the level of noise?

To explore how play varies with the error rate, we now examine our two additional control treatments using $\mathrm{b} / \mathrm{c}=4$ with $\mathrm{E}=1 / 16$ and $\mathrm{E}=0$, and compare them to our results using $b / c=4$ at $E=1 / 8$. We begin by asking whether subjects condition on their partner's play two rounds ago in the last 4 interactions of each session, using a logistic regression with correlated random effects and regressing own decision in round t against other's play in round $\mathrm{t}-2$, own play in $\mathrm{t}-2$, other's play in $\mathrm{t}-1$, own play in $\mathrm{t}-1$, own first round cooperation frequency in the last 4 interactions and own frequency of cooperation in all rounds of the last 4 interactions. As with the $E=1 / 8$ treatments, we find a highly significant and sizable dependence on other's play two rounds ago for $E=1 / 16$ (coeff=1.221, $\mathrm{p}<0.001)$; while in the no-error $\mathrm{E}=0$ control, however, we find no significant dependence on other's play two rounds ago (coeff $=0.387, p=0.247$ ). This provides our first direct evidence that the presence of noise plays an important role in strategy selection, promoting more complicated strategies.

Next we present the MLE results for each strategy in Table 5, as well as aggregated MLE results and descriptive statistics in Table 6. As shown in Table 6, overall cooperation is lower at $\mathrm{E}=1 / 8(59 \%)$ than in the lower error conditions, and these 
differences are statistically significant $(E=1 / 16,82 \%, p<0.001 ; E=0,78 \%, p=0.002)^{41}$. Considering cooperation in the first round, there is somewhat less cooperation at $\mathrm{E}=1 / 8$, but the differences are smaller and either not significant or just marginally so $(E=1 / 8$, $76 \%, \mathrm{E}=1 / 16,87 \%, \mathrm{E}=0,83 \% ; 1 / 8$ vs. $1 / 16, \mathrm{p}=0.050,1 / 8$ vs. $0, \mathrm{p}=0.346)$. We find no significant difference at $E=0$ compared to $E=1 / 16$ in either overall cooperation $(p=0.486)$ or first round cooperation ( $\mathrm{p}=0.338)$. Complementing this aggregate analysis, the share of the non-cooperative strategies ALLD and D-TFT is significantly larger at E=1/8 (23\%) compared to $\mathrm{E}=1 / 16(11 \%, \mathrm{p}=0.001)$, and larger at $\mathrm{E}=1 / 8$ than $\mathrm{E}=0(16 \%, \mathrm{p}=0.191)$ although the difference between $\mathrm{E}=0$ and $\mathrm{E}=1 / 8$ is not significant. ${ }^{42}$ There is also no significant difference between $\mathrm{E}=0$ and $\mathrm{E}=1 / 16(\mathrm{p}=0.297)$.

Turning to leniency, we examine cooperation frequency in the subset of histories in which leniency is possible, as described above in response to Question 5. At $E=0,42 \%$ of the eligible histories show leniency, compared to the significantly higher value of $77 \%$ at $\mathrm{E}=1 / 16(\mathrm{p}=0.001)$ and the marginally significantly higher value of $66 \%$ at $\mathrm{E}=1 / 8$ $(\mathrm{p}=0.052)$. We also find that marginally significantly more eligible histories showed leniency at $\mathrm{E}=1 / 16$ than at $\mathrm{E}=1 / 8(\mathrm{p}=0.071)$. We see similar results when analyzing strategy frequencies. The combined frequency of lenient strategies ALLC, TF2T, TF3T, 2TF2T, Grim2 and Grim3 is significantly lower at $\mathrm{E}=0$ (40\%) than at $\mathrm{E}=1 / 16(82 \%$, $\mathrm{p}<0.001)$ or $\mathrm{E}=1 / 8(63 \%, \mathrm{p}<0.001)$. As with the analysis of histories, we also see significantly more leniency at $E=1 / 16$ than at $E=1 / 8(p<0.001)$.

Considering cooperation frequency in histories with the potential for forgiveness, as described above in the response to Question 5 we also see significantly less forgiveness at $\mathrm{E}=0(19 \%)$ compared to $\mathrm{E}=1 / 16(47 \%, \mathrm{p}<0.001)$ or $\mathrm{E}=1 / 8(32 \%, \mathrm{p}<0.001)$. We find no significant difference in forgiveness between $E=1 / 16$ than at $E=1 / 8$ $(\mathrm{p}=0.298)$. Examining the aggregated MLE frequencies, the forgiving strategies ALLC, TFT, TF2T, TF3T, 2TFT and 2TF2T are less common at $\mathrm{E}=0$ (52\%) compared to $\mathrm{E}=1 / 16$ $(78 \%, \mathrm{p}=0.007)$ and at $\mathrm{E}=1 / 8(57 \%)$ compared to $\mathrm{E}=1 / 16(\mathrm{p}=0.001)$. There is no significant difference between forgiving strategies at $E=0$ and $E=1 / 8(p=0.670)$.

\footnotetext{
${ }^{41}$ For each pairwise comparison of aggregate descriptive statistics, we report the results of a logistic regression over all decisions in lenient/forgiving histories, with an error rate dummy as the independent variable, clustered on both subject and interaction pair.

${ }^{42}$ For each pairwise comparison of aggregated MLE coefficients, we report the results of a two-sample ttest using bootstrapped standard errors of the aggregated coefficients.
} 
In summary, we find that substantial levels of leniency and forgiveness are not unique to the high error rate of $\mathrm{E}=1 / 8$, but are also present at the lower error rate of $\mathrm{E}=1 / 16$. When the error rate is zero, leniency is much less frequent. The somewhat greater leniency and forgiveness at $E=1 / 16$ compared to $E=1 / 8$ is surprising; investigating this issue further is an interesting topic for future study.

Table 5. Maximum likelihood estimates for our $E=0, E=1 / 16$ and $E=1 / 8$ conditions using the last 4 interactions of each session. All specifications use b/c=4. Bootstrapped standard errors (shown in parentheses) used to calculate $p$-values.

$\dagger$ Significant at $p<0.1$, * Significant at $p<0.05$, ** Significant at $p<0.01$.

\begin{tabular}{||cccc||}
\hline & $\mathrm{E}=0$ & $\mathrm{E}=1 / 16$ & $\mathrm{E}=1 / 8$ \\
\hline ALLC & $0.24^{*}$ & 0 & $0.06 \dagger$ \\
& $(0.10)$ & $(0.04)$ & $(0.03)$ \\
\hline TFT & $0.14 \dagger$ & 0.04 & $0.07^{*}$ \\
& $(0.08)$ & $(0.04)$ & $(0.03)$ \\
\hline TF2T & 0 & $0.24 *$ & $0.20^{* *}$ \\
& $(0.02)$ & $(0.10)$ & $(0.07)$ \\
\hline TF3T & 0 & $0.42^{* *}$ & $0.09^{*}$ \\
& $(0.04)$ & $(0.09)$ & $(0.04)$ \\
\hline 2TFT & $0.15^{*}$ & 0 & 0.03 \\
& $(0.07)$ & $(0)$ & $(0.02)$ \\
\hline 2TF2T & 0 & 0.08 & $0.12^{*}$ \\
& $(0)$ & $(0.06)$ & $(0.05)$ \\
\hline Grim & $0.15 \dagger$ & 0.03 & $0.04 \dagger$ \\
& $(0.08)$ & $(0.02)$ & $(0.02)$ \\
\hline Grim2 & $0.16 \dagger$ & 0.09 & $0.05 \dagger$ \\
& $(0.09)$ & $(0.05)$ & $(0.03)$ \\
\hline Grim3 & 0 & 0 & $0.11^{* *}$ \\
& $(0.06)$ & $(0)$ & $(0.04)$ \\
\hline ALLD & $0.07 \dagger$ & 0.05 & $0.23^{* *}$ \\
& $(0.04)$ & $(0.03)$ & $(0.04)$ \\
\hline D-TFT & $0.09^{*}$ & 0.05 & 0 \\
& $(0.04)$ & $(0.03)$ & $(0)$ \\
\hline Gamma & $0.35^{* *}$ & $0.44^{* *}$ & $0.43^{*} *$ \\
& $(0.03)$ & $(0.03)$ & $(0.02)$ \\
\hline \hline
\end{tabular}

To further explore the difference in play between error and no-error games, we reanalyze data from Dal Bó \& Frechette (2011) and Dreber et al. (2008) using our strategy set from Table 2. Doing so finds TFT to be the most common cooperative 
strategy in all but one payoff specification. ${ }^{43}$ Additionally, the aggregate frequency of strategies with memory at most 1 (namely ALLC, TFT, D-TFT, and ALLD) is $76 \%$ in the games without noise (including our $\mathrm{E}=0$ control), compared to only $33 \%$ in our games with noise; this difference is largely driven by lenient strategies, most of which by definition look back more than one round, and have an aggregate frequency of $13 \%$ without noise compared to $57 \%$ with noise. $^{44}$

Table 6. Descriptive statistics of aggregate behavior, as well as aggregated MLE frequencies. All specifications use $b / c=4$. The descriptive statistics for leniency and forgiveness are defined in the text. For MLE aggregation, all strategies other than are ALLD and D-TFT are cooperative; lenient strategies are TF2T, TF3T, 2TF2T, Grim2 and Grim3; forgiving strategies are TFT, TF2T, TF3T, 2TFT and 2TF2T.

\begin{tabular}{|c|c|c|c|}
\hline & $\mathrm{E}=0$ & $\mathrm{E}=1 / 16$ & $\mathrm{E}=1 / 8$ \\
\hline \multicolumn{4}{|c|}{ Descriptive statistics } \\
\hline$\%$ C First Round & $83 \%$ & $87 \%$ & $76 \%$ \\
\hline$\%$ C All Rounds & $78 \%$ & $82 \%$ & $59 \%$ \\
\hline Leniency & $42 \%$ & $77 \%$ & $66 \%$ \\
\hline Forgiveness & $19 \%$ & $47 \%$ & $32 \%$ \\
\hline \multicolumn{4}{|c|}{ MLE aggregation } \\
\hline Cooperative strategies & $84 \%$ & $89 \%$ & $77 \%$ \\
\hline Lenient strategies & $40 \%$ & $82 \%$ & $63 \%$ \\
\hline Forgiving strategies & $53 \%$ & $78 \%$ & $57 \%$ \\
\hline
\end{tabular}

The importance of noise for promoting leniency is also reflected in the postexperimental questionnaire. Many subjects reported cooperating following their partner's first defection because they assumed it was due to error.

\section{Discussion}

\footnotetext{
${ }^{43}$ See Appendix D for MLE results.

${ }^{44}$ Note that here we do find some evidence of longer-memory strategies, while our test based on adding only partner's play two periods ago found an insignificant effect. This may be in part due to the fact that the MLE includes strategies like "Grim" that have a longer memory, and in part to the fact that the no-noise case provides less information about play at many histories. The results are qualitatively equivalent when restricting our attention to the no-noise payoff specifications where TFT risk-dominates ALLD, $62 \%$ of strategies use memory at most 1 , and lenient strategies have weight $20 \%$.
} 
To relate play in the experiment to theoretical predictions, we would like to understand the extent to which the observed distribution of play approximates an equilibrium, and to the extent that play is not an equilibrium, what sorts of alternative strategies would perform better. To that end, we used simulations to compute the expected payoff matrix for the strategies that had non-negligible shares in the MLE estimation, along with a few "exploitive" strategies that struck us as good responses to the commonly used lenient strategies. ${ }^{45}$ The resulting payoff matrices are displayed in Appendix E. We will use this table to compute the expected payoff to each strategy given the estimated frequencies, but first we use it to make some observations about the equilibria of the game. In particular, any strategy that is not a Nash equilibrium in this payoff matrix cannot be a Nash equilibrium in the full game. The converse is of course false, but we will then check which of the strategies that are equilibria of the payoff matrix also are equilibria of the full game.

Using that calculated payoff matrix we see that the lenient-and-forgiving strategy TF2T, which was common when $\mathrm{b} / \mathrm{c}=2.5$ or 4 , is not an equilibrium in any treatment: it can be invaded by DC-Alt (the strategy that alternates between D and C) in all payoff specifications, as well as by ALLD when $b / c=1.5$ and by various "exploitive" strategies that start with D in the other treatments. ${ }^{46}$ Note also that TFT is never an equilibrium, although it is fairly common when $b / c=1.5$ : it is invaded by ALLD when $b / c=1.5$ and by ALLC (!) at other b/c values. This is a reflection of the fact that errors can move TFT into an inefficient 2-cycle.

Of course ALLD is an equilibrium in every treatment, and as discussed in Section II, PTFT is an equilibrium at $\mathrm{b} / \mathrm{c}=4$. Perhaps surprisingly, it turns out that Grim2 is also an equilibrium when $b / c=4$, even though it is not an equilibrium in the game without errors. ${ }^{47}$ Moreover, the range of error probabilities for which Grim2 is an equilibrium

\footnotetext{
${ }^{45}$ Analytic computations of the payoff for two different strategies playing each other is complicated due to the combination of discounting and noise, especially if the strategies look back more than one round and/or have many implicit "states."

${ }^{46}$ This is because the one round of punishment provided by TF2T, multiplied by the increased probability of punishment associated with the first $\mathrm{D}$, is too small to outweigh the short-run gain to deviation. When $\mathrm{b} / \mathrm{c}$ becomes sufficiently large, it does pay to conform to TF2T at histories where the strategy says to cooperate, but then it is also optimal to play $\mathrm{C}$ at histories where TF2T says to play D. Mathematica computations show that TF2T is not an equilibrium in any of our treatments.

${ }^{47}$ Without errors it would be better to play D in the first round and subsequently play Grim2, as the continuation payoff after one D is the same as after no D's at all. However in the presence of errors, the expected continuation payoff to Grim2 is lower in the round following a D, and numerical calculations show that when $\mathrm{b} / \mathrm{c}=4$ and $\delta=7 / 8$, Grim 2 is an equilibrium provided that the error probability is between
} 
increases with b/c. Intuitively, there is more reason to be lenient when the rewards to cooperation are greater, which is consistent with the way overall leniency in the data increases with $\mathrm{b} / \mathrm{c}$.

Of course these equilibrium calculations do not tell us what strategies can persist in a mixed-strategy equilibrium, and they do not tell us which strategies have good payoffs given the actual distribution of play. Table 7 shows the expected payoff of each strategy given the prevailing strategy frequencies. In the $\mathrm{b} / \mathrm{c}=1.5$ treatment, where ALLD is most prevalent, ALLD is also the best response to the prevailing strategy frequencies. Furthermore, the average earnings per round of subjects for whom ALLD is the strategy with the greatest likelihood are significantly higher than other subjects' earnings (coeff $=0.108, p=0.028$ ). ALLD does about as well as the average subject in the $b / c=2$ treatment (coeff $=-0.039, \mathrm{p}=0.672$ ), and is significantly worse at $\mathrm{b} / \mathrm{c}=2.5$ (coeff $=-0.400$, $\mathrm{p}<0.001)$ and $\mathrm{b} / \mathrm{c}=4(\operatorname{coeff}=-0.914, \mathrm{p}<0.001) .{ }^{48} \mathrm{We}$ also see that subjects showed good judgment in avoiding PTFT, which performs very poorly in all treatments.

In the treatments with cooperative equilibria, lenient strategies perform very well. Within each of these treatments, the highest payoff strategy that is played is lenient $(\mathrm{b} / \mathrm{c}=2$, Grim2; b/c=2.5, 2TF2T; b/c=4, TF2T). Furthermore, all common lenient strategies (frequency of $10 \%$ or higher) earn within $1 \%$ of the highest payoff earned by any strategy played in that treatment, except for $2 \mathrm{TF} 2 \mathrm{~T}$ at $\mathrm{b} / \mathrm{c}=2$, which earns $1.6 \%$ less than the highest payoff. Various start-with-D strategies would have been the highest earners $(b / c=2, D-G r i m 3 ; b / c=2.5$ and $b / c=4, D-T F 2 T)$, but these strategies were not played. Perhaps this is because these exploitive strategies do not fit well with subjects' intuitions and heuristics about cooperative play, and only out-performed the cooperative strategies by a very small margin (best cooperative strategy earns $5.3 \%$ less than best exploitative strategy at $b / c=2,0.9 \%$ less at $b / c=2.5$ and $0.2 \%$ less at $b / c=4)$. Given the incomplete learning we observe in all treatments, it may therefore not be such a surprise that subjects did not discover the benefit of these exploitive strategies. Furthermore, given the roughly equal payoffs, subjects might reasonably prefer lenient cooperative

0.0332 and 0.2778 . Moreover, the exploitive but lenient strategy D-Grim2 is also an equilibrium when $\mathrm{b} / \mathrm{c}=4$ and $\delta=7 / 8$, although it is not used. See the online appendix for the Grim2 and D-Grim2 equilibrium calculations.

${ }^{48}$ We report the results of a linear regression over profit in all rounds of all interactions, with an ALLD dummy as the independent variable, clustered on both subject and interaction pair. 
strategies to those that exploit. Exploring the lack of exploitative strategies is an important direct for future work.

Table 7. Observed frequencies and resulting expected payoffs for each strategy. Highest payoff strategy among those that were used is shown in bold; highest payoff strategy among all strategies considered is underlined.

\begin{tabular}{|c|c|c|c|c|c|c|c|c|}
\hline & $\begin{array}{l}\qquad \mathrm{b} / \mathrm{c}= \\
\text { Frequency }\end{array}$ & $\begin{array}{c}=1.5 \\
\text { Expected } \\
\text { payoff }\end{array}$ & $\begin{array}{l}\mathrm{b} / \mathrm{c}= \\
\text { Frequency }\end{array}$ & $\begin{array}{c}=2 \\
\text { Expected } \\
\text { payoff }\end{array}$ & $\begin{array}{l}\qquad \mathrm{b} / \mathrm{c}= \\
\text { Frequency }\end{array}$ & $\begin{array}{l}=2.5 \\
\text { Expected } \\
\text { payoff }\end{array}$ & Frequency & $\begin{array}{l}=4 \\
\text { Expected } \\
\text { payoff }\end{array}$ \\
\hline ALLC & & -1.25 & 0.03 & 6.92 & & 13.27 & 0.06 & 28.13 \\
\hline TFT & 0.19 & 2.40 & 0.06 & 8.71 & 0.09 & 14.64 & 0.07 & 29.01 \\
\hline TF2T & 0.05 & 1.53 & & 8.69 & 0.17 & 14.65 & 0.20 & 29.67 \\
\hline TF3T & 0.01 & 0.90 & 0.03 & 8.44 & 0.05 & 14.53 & 0.09 & 29.56 \\
\hline $2 \mathrm{TFT}$ & 0.06 & 2.87 & 0.07 & 8.59 & 0.02 & 13.58 & 0.03 & 27.08 \\
\hline $2 \mathrm{TF} 2 \mathrm{~T}$ & & 1.86 & 0.11 & 8.89 & 0.11 & 14.72 & 0.12 & 29.62 \\
\hline GRIM & 0.14 & 3.02 & 0.07 & 8.40 & 0.11 & 12.33 & 0.04 & 23.99 \\
\hline GRIM2 & 0.06 & 2.37 & 0.18 & 9.03 & 0.02 & 13.98 & 0.05 & 27.90 \\
\hline GRIM3 & 0.06 & 1.79 & 0.28 & 9.02 & 0.24 & 14.67 & 0.11 & 29.23 \\
\hline ALLD & 0.29 & $\underline{3.73}$ & 0.17 & 8.53 & 0.14 & 11.33 & 0.23 & 21.04 \\
\hline D-TFT & 0.15 & 2.89 & & 9.19 & 0.05 & 14.66 & & 28.76 \\
\hline PTFT & & 0.72 & & 6.34 & & 12.05 & & 25.36 \\
\hline D-TF2T & & 1.93 & & 9.14 & & 14.87 & & 29.73 \\
\hline D-Grim3 & & 2.34 & & $\underline{9.54}$ & & 14.83 & & 28.92 \\
\hline
\end{tabular}

Based on the expected payoffs in Table 7, perhaps the largest surprise is not the success of leniency and forgiveness, but rather the high proportion of subjects playing ALLD, particularly at $\mathrm{b} / \mathrm{c}=4$. The reason that low performing strategies such as ALLD can persist despite receiving low expected payoffs is probably that the complexity of the environment makes it difficult to learn the optimal response. Even though ALLD is not a best response to what people are really doing, ALLD is a best response to a belief that everyone else plays ALLD or any other history-independent strategy, and because of the noisy observation of intended play, subjects who have such false beliefs may not learn that more cooperative strategies yield a higher payoff. Consistent with this, $12 \%$ of subjects defected in more than $85 \%$ of all rounds in all interactions at $b / c=2,9 \%$ of subjects at $b / c=2.5$ and $16 \%$ of subjects at $b / c=4$. This accounts for a substantial fraction of the players classified as ALLD by the MLE, and suggests that these subjects almost 
never experimented with cooperation, preventing them from learning about its benefits. Furthermore, examining the play of these stubborn defectors, we find no positive correlation between first round cooperation and the previous partner's cooperation in the first round of the previous interaction; in fact the relationship is negative, although not significant (coeff=-0.081, $\mathrm{p}=0.882$ ). ${ }^{49}$ Thus meeting a first-round cooperator does not increase these subjects' probability of cooperating in future interactions. This is reminiscent of heterogeneous self-confirming equilibrium (Fudenberg and Levine 1993), and the diversity of strategies is consistent with heterogeneous self-confirming equilibrium in the absence of noise; in the presence of noise similar situations can persist for a while. ${ }^{50}$ A similar logic applies to Grim, which is a best response to the belief that a substantial fraction of the population plays Grim while the rest plays ALLD - a subject who always uses Grim may not learn about the benefits of being more lenient.

We find no difference in first round cooperation between $b / c=2$ and $b / c=2.5$, and that the increase in overall cooperation as b/c increases from 1.5 to 2 is larger than the increase in moving from $b / c=2$ to $b / c=2.5$, even though ALLD risk-dominates TFT at $b / c=2$ but not $b / c=2.5$. Thus the risk dominance criterion has at best limited predictive power regarding cooperation in games with noise.

To explore possible non-strategic motivations for leniency and forgiveness, we examined the subjects' social preferences using a post-experiment dictator game and a set of survey questions from social psychology. In Dreber, Fudenberg and Rand (2010), we show that dictator giving is not correlated with cooperation in histories where there is the possibility of leniency, and not consistently correlated with cooperation in histories with the possibility for forgiveness. Dictator giving is also uncorrelated with both first-round cooperation and overall cooperation in the specifications with cooperative equilibria (where leniency and forgiveness are common). Furthermore, while lenient and forgiving strategies earn high expected monetary payoffs, the Ernst Fehr and Klaus M. Schmidt (1999) model of inequity aversion gives little utility to these strategies. We use this, the

\footnotetext{
${ }^{49}$ When considering only subjects whose realized actions (as opposed to intended actions) resulted in over $85 \% \mathrm{D}$, we also find no correlation between previous partner's first round cooperation and own cooperation in the first round of the present interaction (coeff $=-0.350, \mathrm{p}=0.828$ ).

${ }^{50}$ Evolutionary models such as the replicator dynamic, when applied to repeated games by restricting the strategy set can converge to steady states with multiple strategies present, as in Feldman and Thomas (1987). These polymorphic steady states, however, require that all of the active strategies obtain the same payoff, which is not a good approximation of the situation here.
} 
survey data and additional analysis to argue that social preferences do not seem to be a key factor in explaining the leniency and forgiveness observed in our experiments.

\section{Conclusion}

We conclude that subjects do tend to cooperate in noisy repeated games when there is a cooperative equilibrium, that they cooperate even when there are no cooperative equilibria in memory-1 strategies, and that they cooperate even when TFT is riskdominated by ALLD. This shows that conclusions based on evolutionary game theory models that incorporate the memory- 1 restriction need not apply to play in laboratory experiments, and that subjects can and do use strategies with more complexity. We also see that strategies such as TF2T that involve leniency and forgiveness are both common and rather successful in the sense of obtaining high payoffs given the actual distribution of play, even though it is not an equilibrium for all agents to play TF2T: In an uncertain world, it can be payoff-maximizing to be slow to anger and fast to forgive. 


\section{References}

Abreu, Dilip, David Pearce, and Ennio Stachetti. 1990. "Towards a Theory of Discounted Repeated Games with Imperfect Monitoring." Econometrica, 58(5): 10411064.

Aoyagi, Masaki, and Guillaume Frechette. 2009. "Collusion as public monitoring becomes noisy: Experimental evidence." Journal of Economic Theory, 144(3): 11351165.

Aumann, Robert J., and Lloyd S. Shapley. 1994. "Long-term Competition - a Game Theoretic Analysis." Essays in Game Theory in Honor of Michael Maschler, edited by N. Megiddo, Springer, New York, 1994, pp. 1-15

Axelrod, Robert. 1984. The Evolution of Cooperation. New York: Basic Books.

Axelrod, Robert, and William D. Hamilton. 1981. "The Evolution of Cooperation," Science, 211(4489): 1390-1396.

Binmore, Ken, and Larry Samuelson. 1992. "Evolutionary Stability in Repeated Games Played by Finite Automata." Journal of Economic Theory, 57(2): 278-305.

Blonski, Matthias, and Giancarlo Spagnolo. 2004. "Prisoners' other Dilemma." http://www.gianca.org/Index.htm.

Blonski, Matthias, Peter Ockenfels, and Giancarlo Spagnolo. 2011. "Equilibrium Selection in the Repeated Prisoner's Dilemma: Axiomatic Approach and Experimental Evidence, American Economic Journal: Microeconomics, forthcoming._

Boyd, Robert. 1989. "Mistakes Allow Evolutionary Stability in the Repeated Prisoner's Dilemma." Journal of Theoretical Biology, 136(1): 47-56.

Boyd, Robert, and Jeffrey P. Lorberbaum. 1987. "No Pure Strategy is Stable in the Repeated prisoner's dilemma Game." Nature, 327: 58-59. 
Camera, Gabriele, Marco Casari, and Maria Bigoni. 2010. "Cooperative Strategies in Groups of Strangers: An Experiment." Krannert School of Management Working Paper 1237.

Chamberlain, Gary. 1980. "Analysis of Covariance with Qualitative Data." Review Economic Studies, 47(1): 225-238.

Dal Bó, Pedro. 2005. "Cooperation Under the Shadow of the Future: Experimental Evidence from Infinitely Repeated Games." American Economic Review, 95(5): 15911604.

Dal Bó, Pedro, and Guillaume Frechette. 2011. "The Evolution of Cooperation in Infinitely Repeated Games: Experimental Evidence." American Economic Review, 101(1): 411-429.

Dreber Anna, Drew Fudenberg, and David G. Rand. 2010. "Who Cooperates in Repeated Games?" http://www.economics.harvard.edu/faculty/fudenberg.

Dreber Anna, David G. Rand, Drew Fudenberg, and Martin A. Nowak. 2008. "Winners Don't Punish." Nature, 452: 348-351.

Duffy, John, and Jack Ochs. 2009. "Cooperative Behavior and the Frequency of Social Interaction." Games and Economic Behavior, 66(2): 785-812.

Engle-Warnick, Jim, and Robert L. Slonim. 2006. "Inferring Repeated-Game Strategies from Actions: Evidence from Trust Game Experiments." Economic Theory, 28(3): 603-632.

Feldman, Marcus W., and Ewart A.C. Thomas. 1987. "Behavior-Dependent Contexts for Repeated Plays of the Prisoner's Dilemma II: Dynamical Aspects of the Evolution of Cooperation." Journal of Theoretical Biology, 128(3): 297-315.

Fehr, Ernst, and Klaus M. Schmidt. 1999. "A Theory of Fairness, Competition, and Cooperation." Quarterly Journal of Economics, 114(3): 817-868. 
Feinberg, Robert M., and Thomas A. Husted. 1993. "An Experimental Test of Discount-Rate Effects on Collusive Behavior in Duopoly Markets." Journal of Industrial Economics, 41(2): 153-60.

Fischbacher, Urs. 2007 "z-Tree: Zurich toolbox for ready-made economic experiments." Experimental Economics, 10(2): 171-178.

Friedman, James W. 1971. "A Noncooperative Equilibrium for Supergames." Review of Economic Studies, 38(113): 1-12.

Fudenberg, Drew, and David K. Levine. 1993. "Self-Confirming Equilibrium." Econometrica, 61(3): 523-546.

Fudenberg, Drew, David K. Levine, and Eric Maskin. 1994. "The Folk Theorem with Imperfect Public Information." Econometrica, 62(5): 997-1040.

Fudenberg, Drew, and Eric Maskin. 1986. "The Folk Theorem in Repeated Games with Discounting or with Incomplete Information." Econometrica, 54(3): 533-556.

Fudenberg, Drew, and Eric Maskin. 1990. "Evolution and Cooperation in Noisy Repeated Games." American Economic Review, 80(2): 274-279.

Fudenberg, Drew, and Eric Maskin. 1994. "Evolution and Noisy Repeated Games." http://www.economics.harvard.edu/faculty/fudenberg.

Green, Edward J., and Robert H. Porter. 1984. "Noncooperative Collusion under Imperfect Price Information." Econometrica 52(1): 87-100.

Heckman, James J. 1981. "Structural Analysis of Discrete Data with Econometric Applications." In The incidental parameters problem and the problem of initial conditions in estimating a discrete time-discrete data stochastic process, MIT Press, Cambridge, MA, pp. 179-195.

Imhof, Lorens. A., Drew Fudenberg, and Martin A. Nowak. 2007. "Tit-for-Tat or Win-Stay, Lose-Shift?" Journal of Theoretical Biology, 247(3): 574-580. 
Murnighan, J. Keith, and Alvin E. Roth. 1983. "Expecting Continued Play in Prisoner's Dilemma Games." Journal of Conflict Resolution, 27(2): 279-300.

Nowak, Martin A., and Karl Sigmund. 1990. "The Evolution of Stochastic Strategies in the Prisoner's Dilemma." Acta Applicandae Mathematicae, 20(3): 247-265.

Nowak, Martin A., and Karl Sigmund. 1993. "A Strategy of Win-Stay, Lose-Shift that Outperforms Tit-for-Tat in Prisoner's Dilemma." Nature, 364: 56-58.

Nowak, Martin A., Akira Sasaki, Christine Taylor, and Drew Fudenberg. 2004. "Emergence of Cooperation and Evolutionary Stability in Finite Populations." Nature, 428: 646-650.

Posch, Martin. 1999. "Win-Stay, Lose-Shift Strategies for Repeated Games-Memory Length, Aspiration Levels and Noise." Journal of Theoretical Biology, 198(2): 183-195.

Roth, Alvin E., and J. Keith Murnighan. 1978. "Equilibrium Behavior and Repeated Play of the prisoner's dilemma." Journal of Mathematical Psychology, 17(2): 189 -98.

Wedekind, Claus, and Manfred Milinski. 1996. "Human Cooperation in the Simultaneous and the Alternating Prisoner's Dilemma: Pavlov versus Generous Tit-forTat." Proceedings of the National Academy of Sciences (USA), 93: 2686-2689. 
Appendix A - MLE strategy frequency estimates using simulated data

Table A1. Maximum likelihood estimates for simulated histories. For each b/c ratio, the first column shows the actual frequency in the simulated data, and the second column shows the MLE estimate. Bootstrapped standard errors shown in parentheses.

$\dagger$ Significant at $p<0.1$, * Significant at $p<0.05$, ** Significant at $p<0.01$

\begin{tabular}{|c|c|c|c|c|c|c|c|c|}
\hline & \multicolumn{2}{|c|}{$\overline{b / c=1.5}$} & \multicolumn{2}{|c|}{$\mathrm{b} / \mathrm{c}=2$} & \multicolumn{2}{|c|}{$\mathrm{b} / \mathrm{c}=2.5$} & \multicolumn{2}{|c|}{$\mathrm{b} / \mathrm{c}=4$} \\
\hline & Actual & Estimated & Actual & Estimated & Actual & Estimated & Actual & Estimated \\
\hline ALLC & 0 & $\begin{array}{c}0 \\
(0)\end{array}$ & 0.03 & $\begin{array}{c}0.02 \\
(0.02)\end{array}$ & 0 & $\begin{array}{c}0 \\
(0)\end{array}$ & 0.05 & $\begin{array}{l}0.05^{*} \\
(0.03)\end{array}$ \\
\hline TFT & 0.18 & $\begin{array}{c}0.18 * * \\
(0.05)\end{array}$ & 0.08 & $\begin{array}{c}0.08 * * \\
(0.04)\end{array}$ & 0.08 & $\begin{array}{c}0.08 * * \\
(0.04)\end{array}$ & 0.10 & $\begin{array}{c}0.10^{* *} * \\
(0.04)\end{array}$ \\
\hline TF2T & 0.03 & $\begin{array}{l}0.03 \dagger \\
(0.02)\end{array}$ & 0 & $\begin{array}{c}0 \\
(0)\end{array}$ & 0.17 & $\begin{array}{c}0.19 * * \\
(0.05)\end{array}$ & 0.18 & $\begin{array}{c}0.18 * * \\
(0.05)\end{array}$ \\
\hline TF3T & 0 & $\begin{array}{c}0 \\
(0) \\
\end{array}$ & 0.03 & $\begin{array}{c}0.02 \\
(0.03)\end{array}$ & 0.05 & $\begin{array}{l}0.08^{*} \\
(0.05)\end{array}$ & 0.08 & $\begin{array}{l}0.04 \dagger \\
(0.03)\end{array}$ \\
\hline $2 \mathrm{TF} 2 \mathrm{~T}$ & 0 & $\begin{array}{c}0 \\
(0)\end{array}$ & 0.10 & $\begin{array}{c}0.10 * * \\
(0.04)\end{array}$ & 0.13 & $\begin{array}{l}0.09^{*} \\
(0.05)\end{array}$ & 0.12 & $\begin{array}{c}0.13 * * \\
(0.05)\end{array}$ \\
\hline Grim & 0.22 & $\begin{array}{c}0.22 * * \\
(0.05)\end{array}$ & 0.10 & $\begin{array}{c}0.10 * * \\
(0.04)\end{array}$ & 0.12 & $\begin{array}{c}0.12 * * \\
(0.04)\end{array}$ & 0.03 & $\begin{array}{l}0.03 \dagger \\
(0.02)\end{array}$ \\
\hline Grim2 & 0.03 & $\begin{array}{l}0.03 \dagger \\
(0.02)\end{array}$ & 0.20 & $\begin{array}{c}0.19 * * \\
(0.05)\end{array}$ & 0.02 & $\begin{array}{c}0.02 \\
(0.02)\end{array}$ & 0.07 & $\begin{array}{l}0.07 * \\
(0.03)\end{array}$ \\
\hline Grim3 & 0.08 & $\begin{array}{c}0.08 * * \\
(0.03)\end{array}$ & 0.28 & $\begin{array}{c}0.31 * * \\
(0.06)\end{array}$ & 0.25 & $\begin{array}{c}0.24 * * \\
(0.06)\end{array}$ & 0.12 & $\begin{array}{c}0.14 * * \\
(0.04)\end{array}$ \\
\hline PTFT & 0 & $\begin{array}{c}0 \\
(0) \\
\end{array}$ & 0 & $\begin{array}{c}0 \\
(0)\end{array}$ & 0 & $\begin{array}{c}0 \\
(0) \\
\end{array}$ & 0 & $\begin{array}{c}0 \\
(0)\end{array}$ \\
\hline 2PTFT & 0 & $\begin{array}{c}0 \\
(0)\end{array}$ & 0 & $\begin{array}{c}0 \\
(0)\end{array}$ & 0 & $\begin{array}{c}0 \\
(0)\end{array}$ & 0 & $\begin{array}{c}0 \\
(0)\end{array}$ \\
\hline 2TFT & 0 & $\begin{array}{c}0 \\
(0)\end{array}$ & 0 & $\begin{array}{c}0 \\
(0)\end{array}$ & 0 & $\begin{array}{c}0 \\
(0)\end{array}$ & 0 & $\begin{array}{c}0 \\
(0)\end{array}$ \\
\hline $\mathrm{T} 2$ & 0 & $\begin{array}{c}0 \\
(0)\end{array}$ & 0 & $\begin{array}{c}0 \\
(0) \\
\end{array}$ & 0 & $\begin{array}{c}0 \\
(0)\end{array}$ & 0 & $\begin{array}{c}0 \\
(0)\end{array}$ \\
\hline ALLD & 0.28 & $\begin{array}{c}0.28 * * \\
(0.06)\end{array}$ & 0.17 & $\begin{array}{c}0.17 * * \\
(0.06)\end{array}$ & 0.13 & $\begin{array}{c}0.13 * * \\
(0.05)\end{array}$ & 0.25 & $\begin{array}{c}0.25^{* *} * \\
(0.06)\end{array}$ \\
\hline C-to-ALLD & 0 & $\begin{array}{c}0 \\
(0)\end{array}$ & 0 & $\begin{array}{c}0 \\
(0)\end{array}$ & 0 & $\begin{array}{c}0 \\
(0)\end{array}$ & 0 & $\begin{array}{c}0 \\
(0)\end{array}$ \\
\hline D-TFT & 0.17 & $\begin{array}{c}0.17 * * \\
(0.05) \\
\end{array}$ & 0 & $\begin{array}{c}0 \\
(0) \\
\end{array}$ & 0.05 & $\begin{array}{l}0.05 \dagger \\
(0.03) \\
\end{array}$ & 0 & $\begin{array}{c}0 \\
(0) \\
\end{array}$ \\
\hline D-TF2T & 0 & $\begin{array}{c}0 \\
(0)\end{array}$ & 0 & $\begin{array}{c}0 \\
(0)\end{array}$ & 0 & $\begin{array}{c}0 \\
(0)\end{array}$ & 0 & $\begin{array}{c}0 \\
(0)\end{array}$ \\
\hline D-TF3T & 0 & $\begin{array}{c}0 \\
(0)\end{array}$ & 0 & $\begin{array}{c}0 \\
(0) \\
\end{array}$ & 0 & $\begin{array}{c}0 \\
(0) \\
\end{array}$ & 0 & $\begin{array}{c}0 \\
(0) \\
\end{array}$ \\
\hline D-Grim2 & 0 & $\begin{array}{c}0 \\
(0)\end{array}$ & 0 & $\begin{array}{c}0 \\
(0)\end{array}$ & 0 & $\begin{array}{c}0 \\
(0)\end{array}$ & 0 & $\begin{array}{c}0 \\
(0)\end{array}$ \\
\hline D-Grim3 & 0 & $\begin{array}{c}0 \\
(0) \\
\end{array}$ & 0 & $\begin{array}{c}0 \\
(0) \\
\end{array}$ & 0 & $\begin{array}{c}0 \\
(0) \\
\end{array}$ & 0 & $\begin{array}{c}0 \\
(0) \\
\end{array}$ \\
\hline DC-Alt & 0 & $\begin{array}{c}0 \\
(0)\end{array}$ & 0 & $\begin{array}{c}0 \\
(0)\end{array}$ & 0 & $\begin{array}{c}0 \\
(0)\end{array}$ & 0 & $\begin{array}{c}0 \\
(0)\end{array}$ \\
\hline Gamma & & $\begin{array}{c}0.02 \\
(0.01)\end{array}$ & & $\begin{array}{c}0.02 \\
(0.01) \\
\end{array}$ & & $\begin{array}{c}0 \\
(0.01) \\
\end{array}$ & & $\begin{array}{c}0.05^{* *} \\
(0.01) \\
\end{array}$ \\
\hline
\end{tabular}


Appendix B - Evidence of learning

First, we investigate the extent of learning over the session for each payoff specification using $\mathrm{E}=1 / 8 .{ }^{51} \mathrm{We}$ do this by examining cooperation in the first round of each interaction (Figure 1), because this reflects each subject's strategy independent of the play of their current partner. There is no significant relationship between interaction number and first round cooperation when $\mathrm{b} / \mathrm{c}=1.5$ ( $\mathrm{coeff}=0.006, \mathrm{p}=0.788)$, a significant positive relationship when $\mathrm{b} / \mathrm{c}=2$ (coeff $=0.089, \mathrm{p}=0.001)$, and a non-significant relationship with a nonetheless rather sizable positive coefficient when $b / c=2.5$ $(\operatorname{coeff}=0.056 \mathrm{p}=0.100)$ and $\mathrm{b} / \mathrm{c}=4(\operatorname{coeff}=0.034, \mathrm{p}=0.166)$.

Examining learning at the individual level for the $E=1 / 8$ conditions, we see a significant positive correlation between first round cooperation and the previous partner's cooperation in the first round of the previous interaction (coeff $=0.335, \mathrm{p}<0.001) .{ }^{52}$ Thus meeting cooperative partners tends to make one play more cooperatively, although the effect size is moderate (average probability of first round cooperation after meeting a defector, 65\%; after meeting a cooperator, $72 \%$ ).

We turn now to the lower error rate controls. In the $E=1 / 16$ control, we find a similar relationship between first round cooperation and the previous partner's first round decision (coeff $=0.513, \mathrm{p}=0.047$; after defection, 81\%; after cooperation $88 \%$ ), although there is no overall change in first round cooperation across interactions (coeff $=0.005$, $\mathrm{p}=0.898$ ). For $\mathrm{E}=0$, the opposite is true: there is no significant relationship between first round cooperation and the previous partner's opening move (coeff $=-0.073, \mathrm{p}=0.818)$, but there is a significant increase in cooperation across interactions (coeff $=0.129, \mathrm{p}=0.034)$. Thus there is also evidence of learning in both controls.

\footnotetext{
${ }^{51}$ We report the results from a logistic regression over all individual first round decisions, with the interaction number as the independent variable. To account for the non-independence of observations from a given subject, and from subjects within a given pairing, we clustered on both subject and interaction pair.

${ }^{52}$ The positive correlation between first round cooperation and the previous partner's cooperation in the first round of the previous interaction remains significant (coeff $=0.291, \mathrm{p}=0.001$ ) when controlling for interaction number and $\mathrm{b} / \mathrm{c}$ ratio, and we find no significant interaction either interaction number (coeff=0.016, $\mathrm{p}=0.484$ ) or $\mathrm{b} / \mathrm{c}$ ratio (coeff $=0.0003, \mathrm{p}=0.998$ ). Furthermore, we continue to observe this positive relationship when restricting our analysis to the last 4 rounds of each interaction (coeff $=0.342, p=0.001$ ). Thus the effect of meeting cooperative partners does not appear to vary across interaction or payoff specification.
} 
Appendix C - MLE strategy frequencies using full 20 strategy set

Table A2. Maximum likelihood estimates for the last 4 interactions of each session, all 20 strategies. Bootstrapped standard errors in parentheses.

$\dagger$ Significant at $p<0.1, *$ Significant at $p<0.05$, ** Significant at $p<0.01$

\begin{tabular}{|c|c|c|c|c|c|c|}
\hline & $\begin{array}{l}\mathrm{b} / \mathrm{c}=1.5 \\
\mathrm{E}=1 / 8\end{array}$ & $\begin{array}{c}\mathrm{b} / \mathrm{c}=2 \\
\mathrm{E}=1 / 8\end{array}$ & $\begin{array}{l}\mathrm{b} / \mathrm{c}=2.5 \\
\mathrm{E}=1 / 8\end{array}$ & $\begin{array}{c}\mathrm{b} / \mathrm{c}=4 \\
\mathrm{E}=1 / 8\end{array}$ & $\begin{array}{c}\mathrm{b} / \mathrm{c}=4 \\
\mathrm{E}=1 / 16\end{array}$ & $\begin{array}{l}\mathrm{b} / \mathrm{c}=4 \\
\mathrm{E}=0\end{array}$ \\
\hline ALLC & $\begin{array}{c}0 \\
(0) \\
\end{array}$ & $\begin{array}{c}0.03 \\
(0.03) \\
\end{array}$ & $\begin{array}{c}0 \\
(0.02) \\
\end{array}$ & $\begin{array}{l}0.05 \dagger \\
(0.03)\end{array}$ & $\begin{array}{c}0 \\
(0.05) \\
\end{array}$ & $\begin{array}{l}0.24^{*} \\
(0.10)\end{array}$ \\
\hline TFT & $\begin{array}{c}0.19 * * \\
(0.05)\end{array}$ & $\begin{array}{c}0.07 \\
(0.04)\end{array}$ & $\begin{array}{l}0.09 * \\
(0.04)\end{array}$ & $\begin{array}{c}0.07 * \\
(0.03) \\
\end{array}$ & $\begin{array}{c}0.04 \\
(0.03) \\
\end{array}$ & $\begin{array}{l}0.15^{*} \\
(0.07) \\
\end{array}$ \\
\hline $\mathrm{TF} 2 \mathrm{~T}$ & $\begin{array}{l}0.05 \dagger \\
(0.03) \\
\end{array}$ & $\begin{array}{c}0 \\
(0) \\
\end{array}$ & $\begin{array}{l}0.16^{*} \\
(0.07) \\
\end{array}$ & $\begin{array}{c}0.19 * * \\
(0.06)\end{array}$ & $\begin{array}{l}0.22 * \\
(0.09) \\
\end{array}$ & $\begin{array}{c}0 \\
(0.03) \\
\end{array}$ \\
\hline TF3T & $\begin{array}{c}0.01 \\
(0.01)\end{array}$ & $\begin{array}{c}0.03 \\
(0.03) \\
\end{array}$ & $\begin{array}{c}0.05 \\
(0.04) \\
\end{array}$ & $\begin{array}{l}0.09 * \\
(0.04)\end{array}$ & $\begin{array}{l}0.40 * * \\
(0.11)\end{array}$ & $\begin{array}{c}0 \\
(0.03) \\
\end{array}$ \\
\hline $2 \mathrm{TFT}$ & $\begin{array}{c}0.06 \\
(0.04) \\
\end{array}$ & $\begin{array}{l}0.07 \dagger \\
(0.04)\end{array}$ & $\begin{array}{c}0.02 \\
(0.02)\end{array}$ & $\begin{array}{c}0.03 \\
(0.02)\end{array}$ & $\begin{array}{c}0 \\
(0)\end{array}$ & $\begin{array}{l}0.16^{*} \\
(0.07)\end{array}$ \\
\hline $2 \mathrm{TF} 2 \mathrm{~T}$ & $\begin{array}{c}0 \\
(0.02) \\
\end{array}$ & $\begin{array}{l}0.11 * \\
(0.05)\end{array}$ & $\begin{array}{l}0.11 \dagger \\
(0.06)\end{array}$ & $\begin{array}{l}0.12^{*} \\
(0.06)\end{array}$ & $\begin{array}{c}0.08 \\
(0.07) \\
\end{array}$ & $\begin{array}{c}0 \\
(0) \\
\end{array}$ \\
\hline Grim & $\begin{array}{c}0.14 * * \\
(0.05) \\
\end{array}$ & $\begin{array}{c}0.05 \\
(0.05) \\
\end{array}$ & $\begin{array}{l}0.11^{*} \\
(0.05) \\
\end{array}$ & $\begin{array}{c}0.02 \\
(0.02) \\
\end{array}$ & $\begin{array}{c}0.02 \\
(0.02) \\
\end{array}$ & $\begin{array}{c}0.12 \\
(0.08) \\
\end{array}$ \\
\hline Grim2 & $\begin{array}{l}0.05 \dagger \\
(0.03)\end{array}$ & $\begin{array}{l}0.16^{*} \\
(0.07)\end{array}$ & $\begin{array}{c}0.02 \\
(0.03)\end{array}$ & $\begin{array}{l}0.05 \dagger \\
(0.03)\end{array}$ & $\begin{array}{l}0.09 \dagger \\
(0.05)\end{array}$ & $\begin{array}{l}0.16^{*} \\
(0.08) \\
\end{array}$ \\
\hline Grim3 & $\begin{array}{l}0.06 \dagger \\
(0.03)\end{array}$ & $\begin{array}{c}0.27 * * \\
(0.08)\end{array}$ & $\begin{array}{c}0.24 * * \\
(0.08)\end{array}$ & $\begin{array}{l}0.11^{*} \\
(0.04)\end{array}$ & $\begin{array}{c}0 \\
(0)\end{array}$ & $\begin{array}{c}0 \\
(0.05)\end{array}$ \\
\hline PTFT & $\begin{array}{c}0 \\
(0) \\
\end{array}$ & $\begin{array}{c}0 \\
(0)\end{array}$ & $\begin{array}{c}0 \\
(0) \\
\end{array}$ & $\begin{array}{c}0 \\
(0) \\
\end{array}$ & $\begin{array}{c}0.02 \\
(0.02) \\
\end{array}$ & $\begin{array}{c}0 \\
(0)\end{array}$ \\
\hline 2PTFT & $\begin{array}{c}0 \\
(0)\end{array}$ & $\begin{array}{c}0.03 \\
(0.03) \\
\end{array}$ & $\begin{array}{c}0 \\
(0)\end{array}$ & $\begin{array}{c}0 \\
(0) \\
\end{array}$ & $\begin{array}{c}0.01 \\
(0.02) \\
\end{array}$ & $\begin{array}{c}0 \\
(0)\end{array}$ \\
\hline $\mathrm{T} 2$ & $\begin{array}{c}0 \\
(0) \\
\end{array}$ & $\begin{array}{c}0 \\
(0) \\
\end{array}$ & $\begin{array}{c}0 \\
(0) \\
\end{array}$ & $\begin{array}{c}0 \\
(0) \\
\end{array}$ & $\begin{array}{c}0 \\
(0) \\
\end{array}$ & $\begin{array}{c}0 \\
(0.01) \\
\end{array}$ \\
\hline ALLD & $\begin{array}{c}0.27 * * \\
(0.05)\end{array}$ & $\begin{array}{c}0.17 * * \\
(0.06)\end{array}$ & $\begin{array}{c}0.14 * * \\
(0.05)\end{array}$ & $\begin{array}{c}0.21 * * \\
(0.04)\end{array}$ & $\begin{array}{c}0.05 \\
(0.03) \\
\end{array}$ & $\begin{array}{l}0.06 \dagger \\
(0.03)\end{array}$ \\
\hline C-to-ALLD & $\begin{array}{c}0 \\
(0.01) \\
\end{array}$ & $\begin{array}{c}0.01 \\
(0.02) \\
\end{array}$ & $\begin{array}{c}0 \\
(0) \\
\end{array}$ & $\begin{array}{c}0.01 \\
(0.01) \\
\end{array}$ & $\begin{array}{c}0.02 \\
(0.02) \\
\end{array}$ & $\begin{array}{c}0.02 \\
(0.02) \\
\end{array}$ \\
\hline D-TFT & $\begin{array}{c}0.10^{* * *} \\
(0.04)\end{array}$ & $\begin{array}{c}0 \\
(0) \\
\end{array}$ & $\begin{array}{c}0.03 \\
(0.03) \\
\end{array}$ & $\begin{array}{c}0 \\
(0) \\
\end{array}$ & $\begin{array}{c}0.02 \\
(0.02) \\
\end{array}$ & $\begin{array}{c}0 \\
(0.02) \\
\end{array}$ \\
\hline D-TF2T & $\begin{array}{c}0 \\
(0) \\
\end{array}$ & $\begin{array}{c}0 \\
(0) \\
\end{array}$ & $\begin{array}{c}0.01 \\
(0.02) \\
\end{array}$ & $\begin{array}{c}0 \\
(0) \\
\end{array}$ & $\begin{array}{c}0.02 \\
(0.01) \\
\end{array}$ & $\begin{array}{c}0 \\
(0.03) \\
\end{array}$ \\
\hline D-TF3T & $\begin{array}{c}0.01 \\
(0.01) \\
\end{array}$ & $\begin{array}{c}0 \\
(0) \\
\end{array}$ & $\begin{array}{c}0 \\
(0) \\
\end{array}$ & $\begin{array}{c}0 \\
(0) \\
\end{array}$ & $\begin{array}{c}0 \\
(0) \\
\end{array}$ & $\begin{array}{c}0.04 \\
(0.03) \\
\end{array}$ \\
\hline D-Grim2 & $\begin{array}{l}0.05 \dagger \\
(0.03)\end{array}$ & $\begin{array}{c}0.01 \\
(0.01)\end{array}$ & $\begin{array}{c}0 \\
(0.01)\end{array}$ & $\begin{array}{c}0.01 \\
(0.01)\end{array}$ & $\begin{array}{c}0 \\
(0.01) \\
\end{array}$ & $\begin{array}{c}0 \\
(0)\end{array}$ \\
\hline D-Grim3 & $\begin{array}{c}0 \\
(0)\end{array}$ & $\begin{array}{c}0 \\
(0)\end{array}$ & $\begin{array}{c}0.01 \\
(0.01)\end{array}$ & $\begin{array}{c}0 \\
(0)\end{array}$ & $\begin{array}{c}0.03 \\
(0.03) \\
\end{array}$ & $\begin{array}{c}0.04 \\
(0.03)\end{array}$ \\
\hline DC-Alt & $\begin{array}{c}0 \\
(0) \\
\end{array}$ & $\begin{array}{c}0 \\
(0) \\
\end{array}$ & $\begin{array}{c}0 \\
(0) \\
\end{array}$ & $\begin{array}{c}0.01 \\
(0.01) \\
\end{array}$ & $\begin{array}{c}0 \\
(0) \\
\end{array}$ & $\begin{array}{c}0 \\
(0) \\
\end{array}$ \\
\hline Gamma & $\begin{array}{c}0.46^{* *} \\
(0.02)\end{array}$ & $\begin{array}{c}0.49 * * \\
(0.03)\end{array}$ & $\begin{array}{c}0.49 * * \\
(0.03)\end{array}$ & $\begin{array}{c}0.43 * * \\
(0.02)\end{array}$ & $\begin{array}{c}0.43 * * \\
(0.02) \\
\end{array}$ & $\begin{array}{c}0.34 * * \\
(0.02) \\
\end{array}$ \\
\hline
\end{tabular}


Appendix D - MLE strategy frequencies for previous experiments without noise

Table A3. Maximum likelihood estimates for Dal Bó and Frechette (2011), the twooption control games from Dreber et al (2008) and a b/c=4 no-error control session. For $\delta=1 / 2$, the last 16 interactions were analyzed, and for $\delta=3 / 4$, the last 8 interactions. Bootstrapped standard errors in parentheses. Note that MLE results for our no-noise treatment is shown in the main text, Table 5.

$\dagger$ Significant at $p<0.1$, * Significant at $p<0.05$, ** Significant at $p<0.01$.

\begin{tabular}{|c|c|c|c|c|c|c|c|c|}
\hline & \multicolumn{6}{|c|}{ Dal Bo and Frechette 2011} & \multicolumn{2}{|c|}{ Dreber et al 2008} \\
\hline Payoff & $\mathrm{R}=32$ & $\mathrm{R}=40$ & $\mathrm{R}=48$ & $\mathrm{R}=32$ & $\mathrm{R}=40$ & $\mathrm{R}=48$ & $\mathrm{~b} / \mathrm{c}=1.5$ & $\mathrm{~b} / \mathrm{c}=2$ \\
\hline$\delta$ & 0.5 & 0.5 & 0.5 & 0.75 & 0.75 & 0.75 & 0.75 & 0.75 \\
\hline ALLC & $\begin{array}{c}0 \\
(0) \\
\end{array}$ & $\begin{array}{c}0 \\
(0.01) \\
\end{array}$ & $\begin{array}{c}0.01 \\
(0.02) \\
\end{array}$ & $\begin{array}{c}0 \\
(0) \\
\end{array}$ & $\begin{array}{c}0 \\
(0.02) \\
\end{array}$ & $\begin{array}{c}0.02 \\
(0.04) \\
\end{array}$ & $\begin{array}{c}0 \\
(0) \\
\end{array}$ & $\begin{array}{c}0 \\
(0)\end{array}$ \\
\hline TFT & $\begin{array}{l}0.07 \dagger \\
(0.04) \\
\end{array}$ & $\begin{array}{c}0.06 \\
(0.04) \\
\end{array}$ & $\begin{array}{c}0.24 * * \\
(0.06) \\
\end{array}$ & $\begin{array}{c}0.23 * * \\
(0.07) \\
\end{array}$ & $\begin{array}{l}0.21 \dagger \\
(0.12) \\
\end{array}$ & $\begin{array}{c}0.55^{* *} \\
(0.15) \\
\end{array}$ & $\begin{array}{l}0.15^{*} \\
(0.06) \\
\end{array}$ & $\begin{array}{c}0.40 * * \\
(0.15) \\
\end{array}$ \\
\hline TF2T & $\begin{array}{c}0 \\
(0) \\
\end{array}$ & $\begin{array}{c}0.02 \\
(0.02) \\
\end{array}$ & $\begin{array}{l}0.16^{*} \\
(0.07) \\
\end{array}$ & $\begin{array}{c}0.11 \\
(0.07) \\
\end{array}$ & $\begin{array}{c}0.22 * * \\
(0.06) \\
\end{array}$ & $\begin{array}{c}0 \\
(0) \\
\end{array}$ & $\begin{array}{c}0 \\
(0) \\
\end{array}$ & $\begin{array}{c}0 \\
(0) \\
\end{array}$ \\
\hline TF3T & $\begin{array}{c}0 \\
(0)\end{array}$ & $\begin{array}{c}0 \\
(0.01)\end{array}$ & $\begin{array}{c}0.01 \\
(0.02)\end{array}$ & $\begin{array}{c}0 \\
(0)\end{array}$ & $\begin{array}{c}0 \\
(0.02) \\
\end{array}$ & $\begin{array}{c}0.06 \\
(0.04) \\
\end{array}$ & $\begin{array}{c}0 \\
(0)\end{array}$ & $\begin{array}{c}0 \\
(0)\end{array}$ \\
\hline 2TFT & $\begin{array}{c}0 \\
(0) \\
\end{array}$ & $\begin{array}{c}0.06 \\
(0.04) \\
\end{array}$ & $\begin{array}{c}0 \\
(0) \\
\end{array}$ & $\begin{array}{c}0 \\
(0.02) \\
\end{array}$ & $\begin{array}{c}0.35^{* *} \\
(0.13) \\
\end{array}$ & $\begin{array}{c}0.09 \\
(0.09) \\
\end{array}$ & $\begin{array}{c}0 \\
(0) \\
\end{array}$ & $\begin{array}{c}0 \\
(0) \\
\end{array}$ \\
\hline 2TF2T & $\begin{array}{c}0 \\
(0) \\
\end{array}$ & $\begin{array}{c}0 \\
(0)\end{array}$ & $\begin{array}{c}0 \\
(0.04) \\
\end{array}$ & $\begin{array}{c}0 \\
(0.04) \\
\end{array}$ & $\begin{array}{c}0 \\
(0.06) \\
\end{array}$ & $\begin{array}{c}0 \\
(0) \\
\end{array}$ & $\begin{array}{c}0 \\
(0) \\
\end{array}$ & $\begin{array}{c}0 \\
(0) \\
\end{array}$ \\
\hline Grim & $\begin{array}{c}0 \\
(0)\end{array}$ & $\begin{array}{c}0 \\
(0.02) \\
\end{array}$ & $\begin{array}{c}0 \\
(0)\end{array}$ & $\begin{array}{c}0 \\
(0.02) \\
\end{array}$ & $\begin{array}{c}0.04 \\
(0.06) \\
\end{array}$ & $\begin{array}{c}0.2 \\
(0.12) \\
\end{array}$ & $\begin{array}{c}0.07 \\
(0.04)\end{array}$ & $\begin{array}{c}0.21 \\
(0.16) \\
\end{array}$ \\
\hline Grim2 & $\begin{array}{c}0 \\
(0) \\
\end{array}$ & $\begin{array}{c}0.01 \\
(0.01) \\
\end{array}$ & $\begin{array}{c}0.02 \\
(0.02) \\
\end{array}$ & $\begin{array}{c}0 \\
(0)\end{array}$ & $\begin{array}{c}0 \\
(0.01) \\
\end{array}$ & $\begin{array}{c}0.02 \\
(0.04) \\
\end{array}$ & $\begin{array}{c}0 \\
(0)\end{array}$ & $\begin{array}{c}0 \\
(0) \\
\end{array}$ \\
\hline Grim3 & $\begin{array}{c}0 \\
(0)\end{array}$ & $\begin{array}{c}0.01 \\
(0.01)\end{array}$ & $\begin{array}{c}0.02 \\
(0.02)\end{array}$ & $\begin{array}{c}0 \\
(0)\end{array}$ & $\begin{array}{c}0 \\
(0.01)\end{array}$ & $\begin{array}{l}0.06 \dagger \\
(0.04)\end{array}$ & $\begin{array}{c}0 \\
(0)\end{array}$ & $\begin{array}{c}0 \\
(0)\end{array}$ \\
\hline ALLD & $\begin{array}{c}0.91 * * \\
(0.04)\end{array}$ & $\begin{array}{c}0.76^{* *} \\
(0.06)\end{array}$ & $\begin{array}{c}0.49 * * \\
(0.07)\end{array}$ & $\begin{array}{c}0.66^{* *} \\
(0.07)\end{array}$ & $\begin{array}{l}0.11 * \\
(0.05)\end{array}$ & $\begin{array}{c}0 \\
(0)\end{array}$ & $\begin{array}{c}0.64 * * \\
(0.1)\end{array}$ & $\begin{array}{l}0.3 * * \\
(0.11)\end{array}$ \\
\hline D-TFT & $\begin{array}{c}0.02 \\
(0.02) \\
\end{array}$ & $\begin{array}{l}0.08 \dagger \\
(0.04)\end{array}$ & $\begin{array}{c}0.04 \\
(0.03) \\
\end{array}$ & $\begin{array}{c}0 \\
(0)\end{array}$ & $\begin{array}{l}0.08 \dagger \\
(0.04)\end{array}$ & $\begin{array}{c}0 \\
(0)\end{array}$ & $\begin{array}{c}0.14 \\
(0.09) \\
\end{array}$ & $\begin{array}{c}0.09 \\
(0.07) \\
\end{array}$ \\
\hline Gamma & $\begin{array}{c}0.34 * * \\
(0.04)\end{array}$ & $\begin{array}{c}0.49 * * \\
(0.04)\end{array}$ & $\begin{array}{l}0.4 * * \\
(0.04) \\
\end{array}$ & $\begin{array}{c}0.45 * * \\
(0.04) \\
\end{array}$ & $\begin{array}{c}0.32 * * \\
(0.03)\end{array}$ & $\begin{array}{c}0.28 * * \\
(0.03)\end{array}$ & $\begin{array}{c}0.36^{* *} \\
(0.03)\end{array}$ & $\begin{array}{c}0.42 * * \\
(0.03)\end{array}$ \\
\hline
\end{tabular}


Appendix E - Calculated payoff matrices

Figure A1. Row player's payoff is shown, averaged over $10^{5}$ randomly simulated games using $c=1, e=1 / 8$ and $\delta=7 / 8$. Best response in each column is shown in bold.

\begin{tabular}{|c|c|c|c|c|c|c|c|c|c|c|c|c|c|c|}
\hline$b / c=1.5$ & ALLC & TFT & TF2T & TF3T & 2TFT & 2TF2T & GRIM & GRIM2 & GRIM3 & ALLD & D-TFT & PTFT & D-TF2T & D-Grim3 \\
\hline ALLC & 6.99 & 5.03 & 6.79 & 6.98 & 3.52 & 6.62 & -4.17 & 3.05 & 6.05 & -10.99 & 2.78 & 0.20 & 4.53 & 3.46 \\
\hline TFT & 8.31 & 5.09 & 7.83 & 8.22 & 2.89 & 7.31 & 2.01 & 4.16 & 6.56 & -1.81 & 2.86 & 4.70 & 6.33 & 4.39 \\
\hline $\mathrm{TF} 2 \mathrm{~T}$ & 7.13 & 5.03 & 6.90 & 7.11 & 3.08 & 6.74 & 0.57 & 4.83 & 6.16 & -3.97 & 2.80 & 2.76 & 4.72 & 3.44 \\
\hline TF3T & 7.01 & 5.03 & 6.80 & 6.99 & 3.42 & 6.64 & -0.55 & 4.41 & 6.38 & -5.61 & 2.78 & 1.77 & 4.55 & 3.93 \\
\hline 2TFT & 9.32 & 5.13 & 7.90 & 8.88 & 3.62 & 6.89 & 2.70 & 5.05 & 6.03 & -0.81 & 2.93 & 6.97 & 6.43 & 3.23 \\
\hline $2 \mathrm{TF} 2 \mathrm{~T}$ & 7.24 & 5.05 & 6.92 & 7.19 & 3.23 & 6.65 & 1.08 & 5.03 & 6.31 & -3.19 & 2.81 & 3.97 & 4.76 & 3.72 \\
\hline GRIM & 14.44 & 5.15 & 7.32 & 8.99 & 4.13 & 6.55 & 3.27 & 4.96 & 6.49 & -0.66 & 2.94 & 8.45 & 5.72 & 4.07 \\
\hline GRIM2 & 9.63 & 5.10 & 6.96 & 7.59 & 3.73 & 6.68 & 2.15 & 5.69 & 6.32 & -2.23 & 2.86 & 6.80 & 4.79 & 3.82 \\
\hline GRIM3 & 7.63 & 5.06 & 6.89 & 7.13 & 3.65 & 6.66 & 1.13 & 5.26 & 6.68 & -3.65 & 2.82 & 5.31 & 4.65 & 4.33 \\
\hline ALLD & 18.99 & 5.22 & 8.45 & 10.91 & 3.71 & 7.29 & 3.48 & 5.83 & 7.97 & 1.00 & 2.97 & 10.75 & 6.19 & 5.57 \\
\hline D-TFT & 9.81 & 5.14 & 9.12 & 9.69 & 1.94 & 8.34 & 1.31 & 5.25 & 7.70 & -0.32 & 2.90 & 4.89 & 7.05 & 5.82 \\
\hline PTFT & 11.53 & 5.10 & 7.88 & 9.29 & 1.86 & 6.75 & -0.18 & 2.10 & 4.23 & -5.51 & 2.86 & 5.85 & 6.37 & 1.08 \\
\hline D-TF2T & 8.64 & 5.06 & 8.26 & 8.60 & 1.70 & 7.98 & $\begin{array}{l}-0.54 \\
\end{array}$ & 5.52 & 7.52 & -2.46 & 2.84 & 2.57 & 6.07 & 4.94 \\
\hline D-Grim3 & 9.35 & 5.10 & 8.31 & 8.65 & 2.63 & 7.90 & 0.57 & 6.16 & 8.06 & -2.05 & 2.84 & 6.29 & 6.05 & 5.81 \\
\hline $\mathrm{b} / \mathrm{c}=\mathbf{2}$ & ALLC & TFT & TF2T & TF3T & 2TFT & 2TF2T & GRIM & GRIM2 & GRIM3 & ALLD & D-TFT & PTFT & D-TF2T & D-Grim3 \\
\hline ALLC & 14.00 & 11.37 & 13.71 & 13.97 & 9.35 & 13.50 & -0.93 & 8.73 & 12.71 & -9.99 & 8.37 & 4.95 & 10.71 & 9.31 \\
\hline TFT & 15.31 & 10.18 & 14.53 & 15.17 & 6.68 & 13.70 & 5.28 & 8.67 & 12.51 & -0.81 & 6.64 & 9.57 & 12.15 & 9.01 \\
\hline TF2T & 14.13 & 11.19 & 13.81 & 14.10 & 8.09 & 13.54 & 3.83 & 10.52 & 12.62 & -2.97 & 8.10 & 7.57 & 10.87 & 8.84 \\
\hline TF3T & 14.01 & 11.34 & 13.71 & 13.98 & 9.01 & 13.50 & 2.73 & 10.14 & 13.07 & -4.61 & 8.32 & 6.55 & 10.72 & 9.75 \\
\hline 2TFT & 16.31 & 9.37 & 13.86 & 15.58 & 7.23 & 12.30 & 5.96 & 9.59 & 11.12 & 0.19 & 5.46 & 11.91 & 10.98 & 6.22 \\
\hline $2 \mathrm{TF} 2 \mathrm{~T}$ & 14.23 & 11.00 & 13.78 & 14.17 & 7.92 & 13.30 & 4.36 & 10.69 & 12.78 & -2.20 & 7.83 & 9.06 & 10.82 & 9.11 \\
\hline GRIM & 21.47 & 9.03 & 11.95 & 14.18 & 7.68 & 10.90 & 6.53 & 8.78 & 10.83 & 0.33 & 5.23 & 13.46 & 8.95 & 6.73 \\
\hline GRIM2 & 16.62 & 9.83 & 13.08 & 13.91 & 7.99 & 12.68 & 5.43 & 11.38 & 12.20 & -1.22 & 6.69 & 11.71 & 9.88 & 8.61 \\
\hline GRIM3 & 14.63 & 10.72 & 13.51 & 13.96 & 8.26 & 13.18 & 4.39 & 10.95 & 13.36 & -2.65 & 7.59 & 10.18 & 10.45 & 10.12 \\
\hline ALLD & 25.99 & 7.62 & 11.93 & 15.23 & 5.61 & 10.38 & 5.33 & 8.43 & 11.29 & 2.00 & 4.61 & 15.00 & 8.93 & 8.10 \\
\hline D-TFT & 16.80 & 9.36 & 15.70 & 16.61 & 4.29 & 14.48 & 3.30 & 9.52 & 13.44 & 0.69 & 5.82 & 8.98 & 12.42 & 10.46 \\
\hline PTFT & 18.52 & 10.03 & 13.71 & 15.57 & 5.75 & 12.39 & 3.10 & 6.11 & 8.92 & -4.50 & 6.54 & 11.70 & 11.23 & 4.21 \\
\hline D-TF2T & 15.64 & 10.64 & 15.10 & 15.57 & 5.29 & 14.67 & 1.43 & 10.73 & 13.87 & -1.47 & 7.35 & 6.67 & 12.15 & 10.31 \\
\hline D-Grim3 & 16.33 & 9.91 & 14.66 & 15.42 & 5.51 & 14.12 & 2.53 & 11.38 & 14.62 & -1.05 & 6.90 & 10.49 & 11.66 & 11.62 \\
\hline $\mathrm{b} / \mathrm{c}=2.5$ & ALLC & TFT & $\mathrm{TF} 2 \mathrm{~T}$ & TF3T & 2TFT & $2 \mathrm{TF} 2 \mathrm{~T}$ & GRIM & GRIM2 & GRIM3 & ALLD & D-TFT & PTFT & D-TF2T & D-Grim3 \\
\hline ALLC & 20.99 & 17.71 & 20.63 & 20.96 & 15.19 & 20.36 & 2.36 & 14.41 & 19.41 & $\begin{array}{r}-8.99 \\
\end{array}$ & 13.98 & 9.68 & 16.88 & 15.10 \\
\hline TFT & 22.31 & 15.27 & 21.25 & 22.11 & 10.48 & 20.09 & 8.56 & 13.22 & 18.48 & 0.19 & 10.42 & 14.43 & 17.95 & 13.70 \\
\hline TF2T & 21.14 & 17.35 & 20.71 & 21.08 & 13.09 & 20.36 & 7.10 & 16.20 & 19.05 & -1.96 & 13.42 & 12.41 & 17.00 & 14.23 \\
\hline TF3T & 21.00 & 17.64 & 20.66 & 20.96 & 14.61 & 20.36 & 6.01 & 15.79 & 19.78 & -3.61 & 13.86 & 11.31 & 16.89 & 15.57 \\
\hline $2 \mathrm{TFT}$ & 23.32 & 13.60 & 19.84 & 22.27 & 10.87 & 17.73 & 9.25 & 14.13 & 16.20 & 1.19 & 7.99 & 16.84 & 15.51 & 9.21 \\
\hline $2 \mathrm{TF} 2 \mathrm{~T}$ & 21.23 & 16.93 & 20.63 & 21.15 & 12.61 & 19.95 & 7.60 & 16.41 & 19.21 & -1.20 & 12.85 & 14.15 & 16.87 & 14.52 \\
\hline GRIM & 28.45 & 12.94 & 16.57 & 19.36 & 11.25 & 15.25 & 9.80 & 12.60 & 15.17 & 1.33 & 7.50 & 18.44 & 12.17 & 9.41 \\
\hline GRIM2 & 23.61 & 14.55 & 19.21 & 20.23 & 12.26 & 18.69 & 8.69 & 17.05 & 18.10 & -0.23 & 10.50 & 16.63 & 14.95 & 13.35 \\
\hline GRIM3 & 21.62 & 16.38 & 20.09 & 20.79 & 12.86 & 19.72 & 7.63 & 16.63 & 20.04 & -1.65 & 12.35 & 15.06 & 16.23 & 15.98 \\
\hline AI.T.D & 32.98 & 10.04 & 15.40 & 19.53 & 7.52 & 13.49 & 7.15 & 11.05 & 14.60 & 3.00 & 6.28 & 19.25 & 11.66 & 10.62 \\
\hline D-TFT & 23.80 & 13.59 & 22.28 & 23.53 & 6.61 & 20.61 & 5.26 & 13.82 & 19.17 & 1.69 & 8.70 & 13.06 & 17.78 & 15.11 \\
\hline PTFT & 25.52 & 14.98 & 19.53 & 21.86 & 9.66 & 18.03 & 6.35 & 10.11 & 13.60 & -3.50 & 10.23 & 17.55 & 16.07 & 7.42 \\
\hline D-TF2T & 22.64 & 16.21 & 21.94 & 22.56 & 8.88 & 21.38 & 3.39 & 15.97 & 20.22 & -0.47 & 11.88 & 10.77 & 18.22 & 15.71 \\
\hline D-Grim3 & 23.35 & 14.72 & 21.03 & 22.19 & 8.37 & 20.36 & 4.50 & 16.61 & 21.23 & -0.05 & 10.94 & 14.69 & 17.28 & 17.42 \\
\hline
\end{tabular}

\begin{tabular}{|c|c|c|c|c|c|c|c|c|c|c|c|c|c|c|}
\hline $\mathrm{b} / \mathrm{c}=4$ & ALLC & TFT & TF2T & TF3T & 2TFT & 2TF2T & GRIM & GRIM2 & GRIM3 & ALLD & D-TFT & PTFT & D-TF2T & D-Grim3 \\
\hline ALLC & 41.99 & 36.74 & 41.40 & 41.91 & 32.73 & 40.97 & 12.21 & 31.44 & 39.43 & -6.02 & 30.75 & 23.91 & 35.43 & 32.53 \\
\hline TFT & 43.28 & 30.54 & 41.39 & 42.94 & 21.86 & 39.32 & 18.36 & 26.85 & 36.29 & 3.19 & 21.74 & 29.00 & 35.47 & 27.67 \\
\hline TF2T & 42.11 & 35.82 & 41.40 & 42.01 & 28.08 & 40.78 & 16.95 & 33.25 & 38.47 & 1.04 & 29.42 & 26.79 & 35.44 & 30.37 \\
\hline TF3T & 42.01 & 36.58 & 41.42 & 41.93 & 31.43 & 40.96 & 15.83 & 32.78 & 39.79 & -0.62 & 30.52 & 25.66 & 35.42 & 32.98 \\
\hline 2TFT & 44.30 & 26.31 & 37.72 & 42.35 & 21.69 & 33.96 & 19.02 & 27.69 & 31.42 & 4.20 & 15.60 & 31.61 & 29.17 & 18.21 \\
\hline 2TF2T & 42.24 & 34.77 & 41.16 & 42.05 & 26.64 & 39.89 & 17.43 & 33.47 & 38.60 & 1.80 & 27.87 & 29.39 & 35.02 & 30.67 \\
\hline GRIM & 49.44 & 24.61 & 30.43 & 34.91 & 21.91 & 28.36 & 19.63 & 24.14 & 28.21 & 4.32 & 14.39 & 33.42 & 21.80 & 17.40 \\
\hline GRIM2 & 44.63 & 28.74 & 37.55 & 39.15 & 25.06 & 36.79 & 18.53 & 34.13 & 35.78 & 2.76 & 21.94 & 31.42 & 30.20 & 27.70 \\
\hline GRIM3 & 42.63 & 33.34 & 39.90 & 41.25 & 26.68 & 39.27 & 17.49 & 33.68 & 40.11 & 1.35 & 26.64 & 29.70 & 33.63 & 33.44 \\
\hline ALLD & 53.99 & 17.23 & 25.86 & 32.45 & 13.22 & 22.76 & 12.64 & 18.89 & 24.55 & 6.00 & 11.25 & 31.99 & 19.86 & 18.19 \\
\hline D-TFT & 44.80 & 26.28 & 42.03 & 44.28 & 13.66 & 38.96 & 11.14 & 26.70 & 36.40 & 4.69 & 17.45 & 25.37 & 33.88 & 28.98 \\
\hline PTFT & 46.52 & 29.77 & 37.02 & 40.72 & 21.30 & 34.95 & 16.14 & 22.07 & 27.55 & -0.51 & 21.34 & 35.09 & 30.65 & 16.83 \\
\hline -TF2T & 43.61 & 32.94 & 42.46 & 43.49 & 19.68 & 41.47 & 9.31 & 31.65 & 39.34 & 2.54 & 25.40 & 23.10 & 36.46 & 31.81 \\
\hline D-Grim3 & 44.34 & 29.11 & 40.11 & 42.47 & 16.99 & 39.04 & 10.42 & 32.34 & 40.93 & 2.96 & 23.03 & 27.29 & 34.07 & 34.84 \\
\hline
\end{tabular}

